Engineering Fracture Mechanics 76 (2009): 114-133. doi:10.1016/j.engfracmech.2008.02.003.

\title{
Fail-Safe Design of Integral Metallic Aircraft Structures Reinforced by Bonded Crack Retarders
}

\author{
X Zhang ${ }^{a^{*}}$, M Boscolo $^{a}$, D Figueroa-Gordon ${ }^{\mathrm{b}}$, G Allegri ${ }^{\mathrm{a}}$, PE Irving ${ }^{\mathrm{b}}$ \\ Departments of Aerospace Engineering ${ }^{\mathrm{a}}$ and Materials ${ }^{\mathrm{b}}$, Cranfield University \\ Bedfordshire, MK43 0AL, U.K.
}

\begin{abstract}
:
This paper presents an investigation on the effectiveness of crack growth retarders bonded to integral metallic structures. The study was performed by both numerical modelling and experimental tests. It focuses on aluminium alloy panels reinforced by bonded straps made of carbon-epoxy, glass-epoxy composite materials or a titanium alloy. The goal was to develop a fail-safe design for integrally stiffened skin-stringer panels applicable to aircraft wing structures. The modelling strategy and finite element models are presented and discussed. The requirements that the models should meet are also discussed. The study has focused on establishing the extent of crack retarder benefits, in terms of fatigue crack growth life improvement, by numerical simulation and experimental tests of various crack retarders. The results of predicted fatigue crack growth retardation have been validated by tests of laboratory samples. This study concludes that by bonding discrete straps to an integral structure, the fatigue crack growth life can be significantly improved.
\end{abstract}

Keywords: Integral metallic structure; crack retarders; bonded straps; fail safe, fatigue crack growth life.

\section{Introduction}

Trends in aircraft manufacture are towards creation of integral structures via use of carbon fibre polymer composite materials and in metals via manufacturing processes such as welding, casting and forging, high-speed machining, rather than the traditional riveting [1-2]. This is mainly driven by manufacture cost saving in future metallic aircraft structures. Integral structures also bring the benefits of reduction in part counts, weight saving and simplification in inspection. However, unlike structures fabricated by mechanical fastening techniques, integral structures do not contain redundant structural members that could act as crack stoppers or retarders; they hence lack fail safety capability, and regulators penalise such structures by imposing extra design safety factors. In order to improve damage tolerance capabilities it is important to include fail-safe design features for single load path constructions.

One promising solution is to use selective reinforcement [3-6]. In 1990 Schijve [3] reported his work on bonded crack stopper bands using a fibre-metal laminate named as ARALL made

\footnotetext{
* Corresponding author. Tel.: +44 1234 754621; fax: +44 1234758203.

Email address: xiang.zhang@ cranfield.ac.uk (X. Zhang).
} 
of Aramid fibres and compared the test result with other crack retarders made of two aluminium alloys, 2024-T3 and 7075-T6, and Ti-6Al-4V. The straps were either riveted or bonded to 2024-T3 substrates. Fatigue crack growth tests showed that the best strap materials were the ARALL and the titanium alloy. Recent boost in future aircraft structures has encouraged more research in crack growth retarders for integral structures. Extensive experimental work has been carried out in [4], in which different reinforcement materials (GLARE, AA7075-T762, and carbon-epoxy in a fibre metal laminate) were investigated in fatigue tests of wide aluminium panel with bonded reinforcement straps. These straps were pre-stretched to reduce or reverse the bonding residual stress in the substrate, and in this way the fatigue crack growth (FCG) life was significantly increased. The thinnest panels had the largest reinforcement volume fraction (28\%) and achieved an average life improvement of more than $300 \%$. Aluminium straps on integrally stiffened panels were also tested and the life was improved by $50 \%$ but it demonstrates the necessity of using fatigue insensitive strap materials to eliminate any premature failure of the structure.

Work in [5] reports a numerical simulation of wide skin-stringer panels, which were either integrally machined or mechanically fastened, with the former being reinforced by bonded straps. The study deliberately selected two very different materials to make the straps, i.e. a ductile titanium alloy and a brittle but much stiffer and higher strength unidirectional carbon composite. Although the straps were much narrower $(15 \mathrm{~mm})$ and far fewer than that reported in [4], they had significant beneficial effect on both fatigue crack growth life and residual strength. Further modelling work and experimental tests were carried out to study the effect of curing temperature and bonding process [6]. Meanwhile the concept of integrally machined local pad-ups (or crenellations) on aluminium alloy panels was tested and modelled [7]. Fatigue crack growth rate was reduced significantly. The same concept was also modelled in [8] which focused on the buckling strength performance. In [7] the idea of slanted stringers was proposed to promote crack turning and hence reduce the crack growth rate. In the civil engineering field, pre-stressed carbon-epoxy reinforcements were bonded to steel plate in order to induce compressive stress in the substrate which promotes crack closure and reduces the FCG rate [9]. Parametric study was carried out by FEA to find the influence of the strap thickness and elastic modulus and pre-tension stress level on the crack growth driving force.

Bonding two different materials creates hybrid structures, for which the failure process is complicated. Failure processes include fatigue crack growth in the substrate, disbond failure of adhesive interface, delamination damage within composite material straps, and possible strap failure due to fatigue loads, notch and free-edge effects. There are many design parameters, such as the strap material, strap dimension and position, which influence the fatigue crack growth rate and structural residual strength. It's virtually impossible to model the entire fatigue crack growth history of a full scale structure on a cycle-by-cycle basis; there are many factors that should be taken into account, such as the crack tip plastic deformation and crack closure effect. There is also the load sequence effect arising from spectrum loads. On the other hand, it's equally unrealistic or very expensive to physically test all design configurations with all possible failure scenarios at the design stage; hence a numerical tool is desirable to help the design process and simulate the structural integrity performance. The 
ultimate goal is to reduce the number of large structural tests through small sample tests and improved simulation, and hence, to reduce uncertainties in design allowables.

This paper focuses on crack growth retarders bonded to integral metallic structures typified by skin-stringer panels for aircraft wing applications. The main objective is to develop credible modelling techniques based on the theory of linear elastic fracture mechanics.

\section{Problem statement}

\subsection{Strap reinforced skin-stringer panels}

Preliminary modelling work was carried out on generic skin-stringer panels representing typical aircraft wing skin covers with either riveted or integrally-machined stringers [5]. The skin sheets and stringers were both made of aluminium alloy 2024-T351. Following problems were investigated: (a) fatigue crack growth and residual strength behaviour of these panels containing a skin crack under a broken central stringer and comparison of the fail-safety capabilities; (b) improving fail-safety of the integrally stiffened panel by attaching narrow and thin straps made of a titanium alloy or carbon epoxy composite. The main results are summarised below.

Fig. 1 shows FE calculated stress intensity factor coefficients $(\beta)$ as a function of normalised half crack length for integrally stiffened and riveted panels together with the theoretical solution of un-stiffened panel of the same width. The initial crack length under the central broken stringer was $50 \mathrm{~mm}\left(2 a_{o}\right)$. Computational details can be found in [5]. For both forms of stringer panel, initially the $\beta$ values are much higher than those of an un-stiffened panel due to the broken stringer transferring stress back to the skin sheet. The values of $\beta$ decrease when skin crack approaches the first outer stringer, and at the stringer to skin joint, the $\beta$ value of the integral panel is significantly lower than that of the riveted panel due to the complete rigid connection of stringer to skin. However, $\beta$ value of the integral panel soon increases rapidly after the crack has passed the first outer stringer because of the crack growth along the integral stringer. Once the crack has grown through the stringer web section, the complete failure of the stringer causes an instant increase in $\beta$. In contrast with the integral panel, $\beta$ of the riveted panel decreases as the skin crack grows due to the intact outer stringers picking up more loads from the cracked skin. Beyond the two-bay crack length, stress in the stringer increases rapidly. In [5], stringer failure due to yielding was not modelled; hence the continued decrease in $\beta$ for a six-bay crack length. This provides un-conservative prediction of crack growth. In fact, $\beta$ will increase after the first outer stringer fails due to yielding. The results in Fig. 1 are consistent with an earlier study [10].

Based on the $\beta$ solution, fatigue crack growth life and residual strength for both panels were calculated [5]. Under both constant and variable amplitude loads, the integral panel fails by the fracture criterion at two-bay crack length, whereas the riveted panel has much longer critical crack length (under the design limit load) and much longer crack growth life (almost doubled).

To overcome this problem, adhesively bonded straps were modelled as crack growth retarders as illustrated in Fig. 2 [5]. These straps were made of titanium alloy Ti-6Al-4V or carbon/epoxy 6376C-HTA, $15 \mathrm{~mm}$ wide and $3 \mathrm{~mm}$ thick, and were placed $6 \mathrm{~mm}$ away from 
the skin doubler edge. The Ti-alloy is very ductile hence will cope with larger crack opening displacement while the strap acts like a bridge exerting traction forces to the crack faces; the composite strap is brittle but has very high tensile strength (almost double the Ti-alloy strength), so it can take much greater loads from the cracked skin and the material is about $60 \%$ lighter. Properties representing adhesive FM73 were used to simulate a bonded layer between the strap and substrate. The modelling results show that bonded straps cause reduction of the stress intensity factors by about $25 \%$. Consequently fatigue crack growth rates were reduced even more significantly. Fig. 2 shows the predicted crack growth lives of the integral panels with and without bonded straps.

\subsection{Scope of this investigation}

The above example was a preliminary study to explore the crack retarder capability using estimated strap dimensions and positions. For practical application the material choice and geometry of these crack retarders should be carefully designed; their impact on the overall load transfer, structural stiffness and long-term structural integrity should be studied.

Recently more comprehensive research has been carried out by experimental testing and numerical modelling. Test samples included the middle-crack tension, $\mathrm{M}(\mathrm{T})$, and single edge notch tension, SENT, specimens. The substrates were made of aluminium alloys 2024-T351 and 7085-T7651. Test samples are shown in Fig. 3. The bonded straps were made of three different materials, i.e. carbon fibre reinforced polymer (CFRP), glass fibre reinforced polymer (GFRP), and titanium alloy Ti-6V-4Al (Ti-6-4). Material properties are given in

Tables 1 and 2. Performance of these straps was evaluated in terms of crack growth rate retardation and fatigue life increment. The modelling approach and test results are reported in the following sections.

\section{Modelling Approach}

The analysis is based on the theory of linear elastic fracture mechanics (LEFM) using the finite element method (FEM). Fig. 4 shows a simple bonded structure where a metallic substrate is reinforced by a bonded composite material strap. Under cyclic loads, there are four possible failure modes, i.e. initiation and growth of a lead crack in the metallic substrate, disbond failure in the adhesive interface, delamination damage in a strap made of composite laminate, and fatigue cracking in the straps due to free-edge or notch effects. The main challenge is to model the interactions of different failure mechanisms.

Bonded straps work by two mechanisms. Firstly, when a substrate crack enters and subsequently propagates in a strap covered region, the strap will act like a "stiffener" providing "local stiffening" that adds load carrying capability by transferring load from cracked substrate to strap; hence the crack growth rate will be reduced. Fig. 4a shows this scenario. However, this beneficial effect could be affected by the presence of local thermal residual stresses arising from the bonding and curing process. The second mechanism takes place when the crack has passed the strapped region. The strap behind the crack tip will exert traction forces on the crack surfaces reducing the crack opening displacement, and subsequently the effective value of crack growth driving force $\Delta K$. This is the so-called "crack bridging" effect, see Fig. 4b. The effectiveness of these crack retardation mechanisms 
depends on the strap material properties and geometric parameters. For example, due to the stiffness mismatch of the strap and substrate materials and stress concentration at the strap free edges, a progressive disbond could develop in the interface that will reduce both the local stiffening effect and the strap bridging traction. All these damage scenarios and crack retardation mechanisms have been considered in this study.

\subsection{Stress intensity factor for bonded structures under static load}

Crack tip stress fields are characterised by the crack tip stress intensity factor $(K)$ calculated by the well known expression:

$$
K=\beta \sigma \sqrt{\pi a}
$$

where, $\sigma$ is the nominal applied stress, $a$ half crack length, and $\beta$ the stress intensity factor coefficient (SIFC) which is a function of the sample's geometry. For a uniform stress field, $K$ may be normalised by the factor $K_{o}\left(K_{o}=\sigma \sqrt{\pi a}\right)$ leading to the non-dimensional term $\beta$. Equation (1) is valid only for homogeneous and isotropic materials.

In this study, straps are modelled as stiffeners attached by continuous bonding to the substrate. The stress intensity factor is determined via the calculation of the strain energy release rate $(G)$. For the case of room temperature cure, i.e. without thermal residual stresses, and for fixed strap dimensions, $G$ due to the external stress is $G_{a p p l}$ :

$$
G_{a p p l}=f\left(\sigma, \beta, a, l_{1}, l_{2}\right)
$$

where, $\sigma$ is the nominal applied stress, $a$ half length of the lead crack in substrate, and $l_{l}$ and $l_{2}$ are areas of disbond and delamination.

For a given crack length, $G_{a p p l}$ is calculated by the FEM using the modified virtual crack closure technique (VCCT) [11-12] and taking into account any delamination and disbond damage at a given applied stress and adhesive toughness. The corresponding $K_{\text {appl }}$ for the bonded structure is then determined by the following equation [13]:

$$
\begin{array}{ll}
K_{a p p l}=\sqrt{G_{a p p l} E} & \text { (plane stress) } \\
K_{a p p l}=\sqrt{\frac{G_{a p p l} E}{1-v^{2}}} & \text { (plane strain) }
\end{array}
$$

where $E$ is the elastic modulus and $v$ the Poisson's ratio.

The calculated $K_{\text {appl }}$ is normalised by $K_{o}$ to obtain $\beta$ :

$$
\beta=\frac{K_{a p p l}}{K_{o}}
$$

$K_{o}$ is the SIF for the crack in the absence of the strap in an infinitely large sheet. Therefore $\beta$ is an indicator of the change in SIF produced by the additional stiffness of the strap. However, since disbond/delamination is considered in calculating the $K$ values, $\beta$ is also indirectly 
related to the applied stress because the disbond and delamination damages are functions of the nominal stress.

The action of thermal residual stresses arising from the elevated cure temperature will result in an additional component of stress intensity $K_{\text {res }}$, therefore the actual SIF $K_{a c t}$ under static loading is the sum of that applied via remote loading and that contributed from the residual stress field.

$$
K_{a c t}=K_{a p p l}+K_{r e s}
$$

For simple geometry and loading forms, $K_{a p p l}$ and $K_{\text {res }}$ may be calculated separately by existing solutions, e.g. handbooks, FEM, or the Green's or weight functions.

In this study, $K_{a c t}$ is calculated by the FEM by inputting the applied stress and the residual stress field into the FE models simultaneously. The crack tip strain energy release rate $\left(G_{a c t}\right)$ due to crack extension is:

$$
G_{a c t}=f\left(\sigma, \sigma_{r e s}, \beta, a, l_{1}, l_{2}\right)
$$

and then $K_{a c t}$ can be found by equation (3) by changing the subscript "appl" to "act" for both the $G$ and $K$ variables. Our modelling work (described in the appendix) has shown that $K_{a c t}$ value calculated by eqs. (6) and (3) equals to that obtained by the superposition method by eq. (5).

In order to make comparisons of strap reinforced substrates with and without the cure temperature effect, it is convenient to consider the additional stress intensity $K_{\text {res }}$ as part of the $\beta$ correction factor, which is therefore increased from that value arising from pure geometrical factors.

$$
\beta_{e q}=\frac{K_{a c t}}{K_{o}}
$$

Under static loads, $\beta_{e q}$ is a good indicator of the stress intensity at a given applied stress due to the contribution of additional straps and thermal residual stresses; although $\beta_{e q}$ is not a pure geometrical factor, it has a unique value for a given geometry, applied stress, strap material and thermal residual stress field. Based on this $\beta_{e q}$ factor, the residual strength of a bonded structure can be calculated through the relation of $\beta_{e q}$ vs. $a$. For example, for a given design limit stress $\sigma_{\max }$, the critical crack length $a_{c r i t}$ can be found by:

$$
a_{c r i t}=\frac{1}{\pi}\left(\frac{K_{I C}}{\sigma_{\max } \beta_{e q}}\right)^{2}
$$

where $K_{I C}$ is the material's fracture toughness using a wide panel test.

In this study the thermal residual stress field was calculated by the FEM. The applied thermal load $\Delta T$ is derived based on the theory that it is the drop in temperature, from stress free condition at temperature $T_{o}$ to ambient temperature $T_{a}$, that causes the thermal residual stresses in the adherends. While the manufacturer will specify the cure temperature $T_{c}$, the stress free temperature is not usually given as the material property data; generally, $T_{o}$ is lower than $T_{c}$ [14]. In this study we have assumed $T_{o}=T_{c}$, i.e. the two adherends become a bonded piece at the cure temperature. Since the experimental test was conducted at the 
ambient temperature $T_{a}$, the temperature drop was $\Delta T=T_{a}-T_{o}$. Note that this is a negative value.

\subsection{FE modelling of disbond damage}

Finite element analysis was performed for different lead crack lengths to find the $K_{a c t} v s . a$ (and $\beta_{e q}$ vs. $a$ ) relation under a given applied stress. The commercial code MSC NASTRAN was employed for this calculation. The substrate and straps were modelled by 2D plate/shell elements and the adhesive layer was modelled by the interface elements; each consisting of two rigid elements and three spring elements as shown in Fig. 5. The rigid elements are used to model the adhesive thickness and the spring elements to model the mechanical properties and failure behaviour of the adhesive layer: one for the peel action and two for the shear in the $\mathrm{X}-\mathrm{Z}$ and $\mathrm{Y}-\mathrm{Z}$ planes. This adhesive model was first developed by Tahmasebi [15] to model bonded joints by strength-based analysis. It is adapted in this work for its simplicity of calculating the strain energy release rate and modelling the disbond growth.

In the experimental tests both adhesive disbond and delamination in the composite straps were observed. Disbond failure was, however, more significant than delamination for the three strap materials investigated, thus only the adhesive disbond was modelled by using the interface elements. In principle, delamination can be modelled by the aforementioned method by placing the interface elements in the delamination region. A better method could be to use a degradation law to reduce the stiffness of delaminated straps.

A set of MATLAB subroutines have been coded to model the disbond growth; these subroutines perform post-processing analyses of the NASTRAN delivered FE results by acquiring the values of the spring axial forces and crack tip opening displacements for both the main crack and disbond front and then calculating the strain energy release rate by the modified VCCT method [11-12]. In order to compute the strain energy release rate on the disbond front, initial disbond damage along the strap edge was assumed, which was the local mesh size of $1 \mathrm{~mm}$ and can be regarded as adhesive defect. In that way the strain energy release rate can be computed and the damage extended when following criterion is satisfied:

$$
\left(\frac{G_{I}}{G_{I C}}\right)^{m}+\left(\frac{G_{I I}}{G_{I I C}}\right)^{n} \geq 1
$$

where $G_{I}$ and $G_{I I}$ are the strain energy release rates in mode I and mode II load conditions, respectively, $G_{I C}$ and $G_{I I C}$ the corresponding critical values (fracture toughness), and $m$ and $n$ are material constants, and in this study we have assumed $m=n=1$. If eq. (9) is satisfied for a set of spring elements, then these springs are removed from the FE model to mimic the disbond damage propagation.

Once a new disbond front is determined for the given load and substrate crack length, another FE analysis is performed to calculate the stress intensity factor according to eqs. (2) and (3). Therefore, disbond development is counted as a correction factor for the SIF solution of the lead crack in substrate. Calculation procedures are given in [17].

\subsection{Damage growth under fatigue loading}


Fatigue crack growth life was determined by integrating the Paris law [18] using measured crack growth data for the substrate material under the same stress ratio:

$$
\frac{d a}{d N}=C\left(\Delta K_{a c t}\right)^{n}
$$

where, $\Delta K_{a c t}$ is the stress intensity factor range under cyclic loads, $N$ the number of cycles, and $C$ and $n$ are material constants. $\Delta K_{a c t}$ is obtained by:

$$
\Delta K_{a c t}=\beta_{e q} \Delta \sigma \sqrt{\pi a}
$$

and

$$
R=\sigma_{\min } / \sigma_{\max }
$$

The difference in the $\Delta K_{a c t}$ and $R$ values obtained by above equation from those calculated by the superposition method [e.g. 19] is explained in the Appendix.

For the growth of a disbond between strap and substrate or delamination within a laminate strap under cyclic loads, following equation should be used:

$$
\frac{d l}{d N}=f(\Delta G)
$$

where $\Delta G$ is the range of strain energy release rate under cyclic loads, $l$ the delamination or disbond size. Ideally fatigue delamination growth should be treated as a separate crack front and the growth rate be regarded as independent from that of the lead crack in substrate. An analysis tool should ideally calculate the $d a / d N$ and $d l / d N$ simultaneously. However, for reasons given below we did not choose eq. 12 to predict fatigue delamination growth. Firstly, there are few measured data of this relation for composite materials or adhesive bonds. Delamination damage patterns and growth rates change with different layups and local support conditions. Secondly, for this application (Fig. 4) the stress intensity of the lead crack in the substrate is dominating whereas failure of bonded straps is secondary due to its failure mode. The latter is mostly mode II (in-plane shear) coupled with mode I due to secondary bending caused by one-sided bonding. Therefore the influence of a strap delamination on the SIF of lead crack is relatively small compared to the large and beneficial bridging forces offered by these straps.

Instead of using eq. (12) it was decided to use disbond or delamination damage area as a geometrical factor to further correct the lead crack $K_{a c t}$ as given in eq. (2) or (6). The corrected $K_{a c t}$ represents crack growth driving force with disbond effect, and under cyclic loads $\Delta K_{a c t}$ is then used in the Paris law (eq. 10) to calculated crack growth rates and via integration the $a$ vs. $N$ curve of the reinforced substrate.

For structures under cyclic tension-compression or cyclic compression-compression loads, disbond damage will be subjected to mode I (crack opening) loads and the growth rate of delamination/disbond could be the same magnitude to that of lead substrate crack. In this case, calculations based on eq. 12 and independent of the lead crack growth rate may be necessary. Further research is needed to obtain the material level damage growth rate and calibrate eq. (12) for structural level calculations.

\section{Development of properties to input into the model}




\subsection{Material properties - coupon test data}

Basic coupon test data are required to link the structural fracture driving forces $\left(K, G_{I} \& G_{I I}\right)$ with the material damage growth and toughness properties. Relevant material data used in this study are: substrate fatigue crack growth rates (Paris constants $C$ and $n$ for the given $R$ ratio) and fracture toughness $\left(K_{I C}\right)$ of the substrate material, modes I and II toughness in terms of critical strain energy release rates of delamination growth within a composite strap $\left(G_{I C} \&\right.$ $\left.G_{I I C}\right)$, toughness of the adhesive bond $\left(G_{I C} \& G_{I I C}\right)$. Data used in this study and the data sources are given in Tables 1 and 2 for the substrate and strap materials, respectively.

\subsection{Residual stress developed during strap bond cure}

The high strength and toughness adhesives used to bond the straps require an elevated temperature cure (typically $70-120^{\circ} \mathrm{C}$ ), resulting in tensile residual stresses in the substrate. To estimate their magnitude, residual stress distributions for the fatigue test sample geometry shown in Fig. 3(b) were modelled using 2D plate finite elements. The plates were made of 7085 aluminium, $10 \mathrm{~mm}$ thick, $140 \mathrm{~mm}$ wide with straps of unidirectional CFRP, GFRP, and titanium alloy Ti-6-4, bonded to the surface at the locations shown. The straps were $200 \mathrm{~mm}$ long, $20 \mathrm{~mm}$ wide and $2 \mathrm{~mm}$ thick. The samples were cured at $120^{\circ} \mathrm{C}$. The residual stresses developed will be a function of the difference in the coefficient of thermal expansion (CTE) between substrate and strap, the stiffness of the two materials, and the curing temperature.

Profiles of calculated longitudinal residual stress $\left(\sigma_{y y}\right)$ of the sample half way along the length for the three strap materials are shown in Fig. 6 (Fig. 6a for a sample of the same dimension of the SENT but without the notch and $6 \mathrm{~b}$ for SENT sample with $17 \mathrm{~mm}$ long initial notch as shown in Fig. 3b). These are the stress values in the middle of the thickness calculated by the 2D plate elements. For the un-notched sample (Fig. 6a), two effects can be seen. Firstly, as the strap is bonded with the centreline of the strap $23 \mathrm{~mm}$ from the centre line of the substrate, there is an in plane bending stress developed in the substrate. Secondly, there is a local enhancement of stress under the strap, present in the titanium and the GFRF, but not noticeably in the CFRP. For the notched samples ( $a_{o}=17 \mathrm{~mm}$, Fig. 3b), the notch tip stresses are much higher than those under the strap due to stress concentration effect. It should be noted that the sum of the residual stresses is not zero. This is the main difference between a welding process and adhesive curing process. For welding the sum of the residual stresses must be zero since no external force is applied and the structure must be in self equilibrium. In this case, residual stress is exerted by the strap on to the substrate; hence for the substrate it is like an external force. Obviously, if the whole bonded structure is considered, the sum of residual stresses will be zero, i.e. compression in the strap and tension in the substrate.

The effect of residual stress on the stress intensity factor at particular crack lengths cannot be interpreted from the immediate local residual stress at the crack tip, but is a consequence of the integrated effect of the entire distribution on $K_{\text {res }}$, the component of stress intensity resulting from the action of the residual stress. The actual stress intensity factor $K_{a c t}$ under static loading is therefore the sum of that applied via remote loading and that contributed from the residual stress field as given by eq. (5). During fatigue testing crack lengths were measured experimentally by the electrical potential technique, which measures a crack length averaged through the sample thickness, corresponding to the length again at mid thickness. 
Thus the measured crack lengths and calculated residual stress fields are both relevant to the mid thickness of the sample.

Figure 7 shows for the titanium strap, the $\beta$ correction factors due purely to sample and crack geometry, the factor caused by geometry plus the additional strap stiffness, and the factor resulting from the geometry, strap stiffness and residual stresses. It can be seen that in the absence of residual stress, the stiffness of the strap causes the $\beta$ factors to reduce at all crack lengths; addition of thermal residual stress causes the $\beta$ to increase for all crack lengths, and in the region where the crack tip is approaching the edge of the strap and tunnelling under it, the $\beta$ is greater than the value without the strap present. This implies that cracks will accelerate in this region, rather than be retarded.

A comparison of the combined $\beta$ factor vs. crack length for all three strap materials is shown in Fig. 8. Both the GFRP and CFRP straps follow the same trends as the titanium strap shown in Fig. 7. The region where the crack tip is approaching the strap has $\beta$ values greater than the sample without the strap; as the crack grows through the strap, $\beta$ reduces, reaching a minimum as it emerges from the strap and it steadily increases as the crack progresses further but always with a value less than the un-strapped sample. The largest $\beta$ is that of the CFRP strap.

\section{Fatigue crack growth tests}

\subsection{Test samples and test procedure}

Two fatigue crack growth test configurations were used. One sample (shown in Fig. 3(a)) was of $\mathrm{M}(\mathrm{T})$ geometry, made of $1.6 \mathrm{~mm}$ thick 2024-T351. It was reinforced by straps made of unidirectional M21-T800 CFRP. They were $200 \mathrm{~mm}$ long and $25 \mathrm{~mm}$ wide, bonded either side of the centre notch with the strap edge $45 \mathrm{~mm}$ from the centreline. The $\mathrm{M}(\mathrm{T})$ samples were bonded using REDUX 810 and were cured at either room temperature (RT) or $70^{\circ} \mathrm{C}$. The second sample was SENT geometry made of $10 \mathrm{~mm}$ thick 7085-T7651 alloy, rigidly clamped at the ends, with the dimensions shown in Fig. 3(b). It should be noted that this is not the ASTM standard SE(T) sample geometry. The strap was $20 \mathrm{~mm}$ wide and $200 \mathrm{~mm}$ long, and the strap edge was $37 \mathrm{~mm}$ from the sample edge. In this test sample the strap materials were unidirectional CFRP Cycom 919HF-42\%-HS, unidirectional Hexcel 913 GFRP and Ti$6 \mathrm{Al}-4 \mathrm{~V}$ titanium alloy. Stiffness and strength properties of the strap materials are given in Table 2. Straps were bonded to the substrate using procedures described in detail in [16], using FM 94 adhesive and were cured at $120^{\circ} \mathrm{C}$.

After bonding, the samples were cyclically loaded in digitally controlled fatigue test machines of capacity 100 and $250 \mathrm{kN}$, at an $R$ ratio of 0.1 and a frequency of $10 \mathrm{~Hz}$. Crack lengths were monitored as a function of fatigue cycles using both electrical potential techniques and optical measurement with a travelling microscope. The nominal stress applied to the samples was 70 MPa for the $1.6 \mathrm{~mm} \mathrm{M(T)} \mathrm{samples} \mathrm{and} 18.57 \mathrm{MPa}$ for the $10 \mathrm{~mm}$ SENT.

\subsection{Fatigue crack growth results}

(a) $\mathrm{M}(\mathrm{T})$ samples 
Figure 9 shows a plot of crack length vs. fatigue cycles for two thicknesses of strap: a single ply $\left(0.25 \mathrm{~mm}\right.$ thick) and a double ply $(0.5 \mathrm{~mm})$, and for the cures at $70^{\circ} \mathrm{C}$ and room temperature. Also shown is the crack growth curve for a panel without a strap. For the room temperature cure without thermal residual stress there is significant crack retardation and increased fatigue life, with 0.25 and $0.5 \mathrm{~mm}$ thick straps extending the life by factors of 2 and 3 respectively. In contrast the panel cured at $70^{\circ} \mathrm{C}$ with residual stresses present showed a decrease in life for the $0.25 \mathrm{~mm}$ strap and a slight increase for the $0.5 \mathrm{~mm}$ strap. It can be concluded that the residual stresses are responsible for a reduction in life by a factor of 3 compared with the lives obtained without them in the room temperature cure. Both with and without residual stress, longer lives were obtained with the thicker straps, which are of course stiffer and offer greater resistance to crack opening. The trade-off between the strap stiffness and cure temperature induced tensile residual stress needs further parametric study.

(b) SENT samples

All the $10 \mathrm{~mm}$ thick SENT samples were cured at $120^{\circ} \mathrm{C}$. Figure 10 shows the measured crack length vs. cycles data for these samples for three different strap materials. Also shown is the crack growth curve for the 7085 aluminium without a strap. Figure 10 shows that in terms of total life, the un-strapped material is the worst and Ti-6-4, the best. Of the composite straps, CFRP is only marginally better than the un-strapped material, and GFRP is significantly better. It was observed experimentally that as the crack tip progressed under the strap, an adhesive disbond developed separating the strap from the substrate. This has the effect of decreasing the effective stiffness of the strap, and allowing the effective $\Delta K$ (expressed as the $\beta$ value) of the crack tip to increase slowly back to the original un-strapped values.

\section{Comparison of experimental and predicted fatigue crack growth behaviour}

\section{$6.1 \mathrm{M}(\mathrm{T})$ sample}

The disbond between the CFRP strap and the substrate revealed after complete sample failure is shown in Fig. 11(a). The disbond length modelled using FE is also illustrated in the figure and the calculated disbond length shows good agreement with that found in experiments. Calculated $\beta$ values (Fig. 11b) show significant differences depending on whether a disbond was allowed to develop at a rate depending on the assumed toughness of the polymer matrix, or whether the strap remained intact as the fatigue crack length increased (assuming infinite fracture toughness).

Fatigue crack growth life was then calculated by integrating the Paris law, eq. (10). A comparison of predicted and measured crack length versus fatigue cycles is shown in Fig. 11c for the case of a CFRP strap with a room temperature cure (without thermal residual stress), and allowing a disbond to develop; there is generally good agreement of the model with the test data, although the model predicts considerably faster crack growth rate than those found experimentally for the region where the crack tip is under the strap. This seems to contradict with the calculated $\beta$ trend in Fig. 11b, where $\beta$ is permanently decreased when crack tip is in the strap region. This may be explained by calculating the second derivative of the " $a-N$ " curve as function of crack length $a$ by using the Paris law. It can be seen from Fig. 11b that $d \beta / d a<0$ when crack tip is in the strap region, therefore the second derivative of the " $a-N$ " 
curve $\left(d^{2} a / d N^{2}\right)$ in this region is negative. This means that the " $a-N$ " curve (Fig. 11c) is convex instead of the concave shape found experimentally. Since such crack growth acceleration was not observed by the test, it could be either that the real $\beta$ function does not decrease in the same way as it was computed or that the material $\mathrm{da} / \mathrm{dN}$ data should not be approximated by a straight line as described by the Paris law, which we currently use. Our tests have shown that for the aluminium alloy the da/dN data is not a straight line [20] and when we use the measured da/dN curve we do not predict the local enhanced convex curve; this matter is currently under investigation.

\subsection{SENT samples}

The predicted fatigue crack length vs. cycles behaviour and the test result for the CFRP strap case are presented in Fig. 12a. As in the case of the $M(T)$ samples, in the region under the strap predicted crack lengths are greater than experimental ones, while with the crack tip beyond the strap crack lengths are under predicted. When using CFRP straps by elevated temperature cure, there is little overall retardation (17\%) developed.

The Ti-6Al-4V straps have significant ductility (>10\%) compared with both CFRP (1-2\% ductility) and GFRP (2-4\%), and will be subject to local yielding at the site of the advancing substrate crack. The FE simulation in [5] shows that the straps are subject to considerable plastic deformation when the crack has passed the straps. Compared to high strength but brittle carbon composite, ductile Ti alloy picks up loads gradually from the cracked substrate, i.e. yielding will limit the elastic stress in the strap. Therefore the stress transfer in adhesive bond should be lower than that in a brittle carbon strap resulting in smaller disbond area and hence lower $\beta$ values. In our FE models, the effect of plastic deformation in the Ti alloy strap was modelled by computing the von Mises equivalent stress and comparing it with the material yield strength (uniaxial test data). Numerical iterations are performed based on the non-linear material stress-strain curve until the true elasto-plastic stress values in the Ti-strap are found.

Figure $12 \mathrm{~b}$ shows that the predicted FCG life for the Ti-alloy strap is in good agreement with the test result, although as for the case of the CFRP strap, the predicted fatigue crack lengths under the strap region are significantly greater than those found experimentally and are predicted to be greater than the un-strapped sample. Once the crack tip was outside the strap zone, crack growth retardation became significant, as was predicted by the model. Overall FCG life is increased by almost $65 \%$ for this strap material.

The life improvement achieved by the unidirectional CFRP was not as good as that achieved by the Ti-alloy strap due to two factors. Firstly, the biggest mismatch in the stiffness and CTE between the CFRP strap and substrate materials results in higher tensile residual stress as shown in Fig. 6 and discussions in Section 4.2. Consequently the crack growth driving force (Fig. 8) and crack growth rates were increased in the early stage of the crack growth life. A small crack growth acceleration was found experimentally in the strap covered region (Fig. 12a), and a much larger one is predicted. 
The crack growth retardation subsequent to the strap region was significantly smaller for the CFRP than for the Ti alloy strap. FE modelling of local stresses and failure progression in CFRP shows that that this is caused by the bigger mismatch in the CTE between the CFRP strap and substrate materials resulting in higher crack growth driving force (Fig. 8). The stiffness mismatch between the substrate and CFRP strap also contributes to this effect [17]. Both mismatch effects promote large shear stresses in the bond and lead in turn to delamination damage within the CFRP strap and also in the adhesive bond. Since the matrix material in the composite is not as tough as the adhesive (Table 2), there is more delamination within the laminate. Damaged straps cannot effectively transfer stresses from cracked substrate to the straps and hence there will be in less traction force for crack bridging. On the other hand, the titanium straps have a smaller stiffness mismatch, but also will have no tendency to create a delamination within the titanium strap. Instead the delamination will occur within the adhesive bond; a location with a much higher mode II toughness and resistance to delamination growth. The value for the mode II toughness of the adhesive used (FM94) has been measured at Cranfield [21] using a modified 3 point End Notched Flexure test in the course of this work to be in excess of $9,000 \mathrm{~J} / \mathrm{m}^{2}$, which is much tougher than that of the matrix material in the CFRP laminate.

Modelling studies have shown that the stiffer the strap, the greater the bridging effect [17]. However, a high stiffness strap will also encourage more stress transfer from the substrate to the strap; this could promote disbond failure. Therefore, a trade-off between the adhesive strength and strap stiffness should be sought. In the configurations examined in [17] plates reinforced by unidirectional CFRP straps were predicted to fail due to early disbond as the assumed adhesive toughness was too low (it was REDUX 810); a thicker cross-ply strap (with much lower stiffness) could obtain the same FCG life and avoid early strap disbond. Factors that promote disbond failure were examined in [17] and it was found that this is mainly due to the mismatching of stiffness between substrate and strap and, secondly, the strong anisotropy of the unidirectional laminates. If the adhesive is tough enough to be able to take very high shear stress, unidirectional carbon-epoxy would be the best material. If disbond is the critical failure mode, then cross-ply, $[0,90]_{\mathrm{ns}}$, carbon composite is the best choice. Angle-ply carbonepoxy composites do not make good straps.

For the glass-epoxy composite strap case, the predicted crack growth life and comparison with the test result is presented in Fig. 12c. The life improvement is not as good as that achieved by the Ti alloy strap but significantly better than the carbon strap. The test shows a life improvement of about $36 \%$ compared with the un-strapped material. In this case crack growth acceleration due to curing temperature effect was well predicted. Crack growth retardation due to bridging was over estimated.

In summary, the ductile Ti-6-4 alloy strap is the best of the three strap materials in terms of FCG life improvement. CFRP strap reinforcement could provide effective crack growth retardation if cured at the room temperature. However, galvanic corrosion is a concern for long-term durability when bonding carbon-epoxy composites to aluminium structures. Another design criterion is the notch strain to failure limit. Since there are holes in the aluminium structure as well as in the reinforcement straps, the realistic maximum strain of a 
metallic wing box at ultimate load is about $2.0-2.5 \%$. The maximum notch strain to failure of carbon fibre composites is around $0.8-1.0 \%$. Hence if we use a strap that has a blunt notch strain to failure much below that of the metallic structure, we could either risk the failing of strap before reaching the structure's ultimate load or have to limit the maximum design strain allowable for the metallic structure resulting in very conservative design. GFRP strap could be a good compromise option in view of the above points.

\section{Conclusions}

Overall, bonded straps are effective in retarding fatigue crack growth rates. The retardation effect is present from the beginning, but becomes much more significant when straps are behind the advancing crack tip, the so-called bridging effect.

In samples containing tensile residual stress produced by elevated temperature cure, the beneficial stiffening effect of bonded straps is adversely affected. Consequently in the strapped region crack growth retardation can be much reduced or even cancelled by temporary crack growth acceleration. The bridging effect overtakes the thermal residual stress as soon as the crack tip grows beyond the strap.

High strength Ti-6Al-4V alloy straps are the most effective crack retarders but it adds more structural weight. Unidirectional carbon epoxy strap cured at elevated temperature provides the least effective crack growth retardation. The galvanic corrosion and low notch strain to failure limit could also be concerns in design applications. Straps made of glass epoxy composite could be a good choice in terms of both crack growth retardation and structural weight.

\section{Acknowledgements}

The authors are grateful to Airbus UK, Alcoa Inc. and the Engineering and Physical Sciences Research Council (through the Cranfield IMRC funding) for providing financial support.

\section{Appendix A}

\section{A.1. Two methods for calculating $\Delta K$ in the presence of residual stress field}

The classic method was proposed by Parker [19] based on the superposition principle of LEFM. The effective SIF is calculated by superposing the respective SIF's for the applied stress and initial residual stress field (eq. A1) and under cyclic load the SIF range and "effective" R-ratio are given in eqs. A2, A3:

Under static load: $\quad K_{\text {effl }}=K_{\text {app }}+K_{\text {res }}$

Under cyclic load: $\quad \Delta K_{e f f}=\left(K_{a p p}^{\max }+K_{r e s}\right)-\left(K_{a p p}^{\min }+K_{r e s}\right)\left[=\Delta K_{a p p}\right]$

$$
R_{\text {eff }}=\left(K_{\text {app }}^{\min }+K_{\text {res }}\right) /\left(K_{\text {app }}^{\max }+K_{\text {res }}\right)\left[\neq \sigma_{\min } / \sigma_{\max }(\text { stress } \cdot \text { ratio })\right]
$$

Therefore under the cyclic loads, only the "effective" stress ration $R_{\text {eff }}$ changes due to $\sigma_{\text {res }}$, Glinka [22]. However, this $R_{\text {eff }}$ ratio is not the same as the original stress ratio $R$. Question arises 
on how to use the measured $d a / d N-\Delta K$ data that is based on the cyclic stress $R$ ratio to calculate crack growth rates.

The method used in this study is based on the superposition of the two stress fields, i.e. externally applied and residual stresses are simultaneously inputted into the FE model. The strain energy release rate $G$ and $K_{a c t}$ are then calculated by eqs. 6 and 3. This method is convenient for using the FEM to do just one calculation for each crack length to find $K_{a c t}$; moreover, the FEA can model residual stress relaxation when crack extends.

Under static stress $\sigma_{o}: \quad K_{a c t}=f\left(G_{a c t}, E, v\right)$

Normalising by $K_{o}=\sigma_{o} \sqrt{\pi a}$, find:

$$
\beta_{e q}=\frac{K_{a c t}}{\sigma_{o} \sqrt{\pi a}}
$$

Under cyclic stress $\Delta \sigma_{o}$ :

$$
\begin{aligned}
& K_{\max }=\beta_{e q} \sigma_{\max } \sqrt{\pi a}, \quad K_{\min }=\beta_{e q} \sigma_{\min } \sqrt{\pi a} \\
& \Delta K_{a c t}=\beta_{e q} \cdot \Delta \sigma \sqrt{\pi a} \quad\left[\neq \Delta K_{a p p}\right] \\
& R_{a c t}=\sigma_{\text {min }} / \sigma_{\text {max }}[=R(\text { stress } \cdot \text { ratio })]
\end{aligned}
$$

Our FE modelling has shown that under static load, the two superposition methods deliver the same value of $K$, i.e. $K_{a c t}=K_{\text {eff, }}$ therefore taking eq. A1 into eq. A5 we get:

$$
\beta_{e q}=\frac{K_{a c t}}{\sigma_{o} \sqrt{\pi a}}=\frac{K_{a p p}+K_{r e s}}{\sigma_{o} \sqrt{\pi a}}=\beta+\frac{K_{r e s}}{\sigma_{o} \sqrt{\pi a}}
$$

$\beta_{e q}$ depends on the pure geometric factor $\beta$, and also on $K_{\text {res }}$ and $\sigma_{o}$. Under the static load, $\beta_{e q}$ is a good indicator of non-dimensional $K_{a c t}$ that is independent of applied stress $\sigma_{o}$; convenient for making comparisons among different design geometries, and for calculating the residual strength at a given applied stress or a given critical crack length.

Under cyclic loads, eq. A6 has "enlarged" the effect of $K_{\text {res }}$ on $\Delta K_{a c t}$ by scaling up $K_{\max }$ and $K_{\min }$ by factor $\beta_{e q}$ (not $\beta$ ); $\beta_{e q}$ contains the effect of $K_{\text {res }}$ and external applied stress $\sigma_{o}$. However, the $R$ ratio remains the same as the original applied stress ratio, i.e. $R<R_{e f f}$.

\section{A.2. Comparison of the two methods}

To compare the two methods in predicting fatigue crack growth rate, constant amplitude load case is used and the static stress $\left(\sigma_{o}\right)$ in eq. A4 is now replaced by the maximum stress $\left(\sigma_{\max }\right)$ in our calculation reported below and in the paper. Taking eq. A9 into eq. A7, we have:

and eq. A8 is:

$$
\Delta K_{a c t}=\Delta K_{a p p}+K_{r e s}(1-R)
$$

$$
R=\sigma_{\min } / \sigma_{\max }
$$

The difference between the classic superposition method (eqs. A2, A3) and our method (A10, A11) is that

$$
\Delta K_{a c t}>\Delta K_{e f f}, R_{a c t}=R\left(<R_{e f f}\right)
$$


Examining Eq. (A10), the following can be stated. Firstly, although the $\Delta K_{a c t}$ is increased by factor $K_{\text {res }}(1-R)$, which will predict higher crack growth rate than the classic method, $R$ ratio remain unchanged and lower than $R_{e f f}$, which will compensate by predicting lower growth rate. Secondly, when $R$ is large (say $\mathrm{R}>0.6$ ) and $K_{\text {res }}$ is low, then the difference between $\Delta K_{a c t}$ and $\Delta K_{\text {eff }}$ is small to make the predicted crack growth rates close.

\section{References}

1. Schmidt, H-J, Voto, C, Hansson, J. TANGO metallic fuselage barrel validation of advanced technologies, Design for Durability in the Digital Age, Proc. $21^{\text {st }}$ Symposium of the International Committee on Aeronautical Fatigue, ICAF 2001, Vol. 1, pp. 273-288, Ed. J. Rouchon, Pub. Cepadues-Editions.

2. Schmidt, H-J, Schmidt-Brandecker, B. Damage tolerance design and analysis of current and future aircraft structure, AIAA/ICAS International Air and Space Symposium and Exposition: The next 100 Years, 14-17 July 2003, Dayton, Ohio. AIAA 2003-2784.

3. Schijve, J. Crack stoppers and ARALL laminates, Eng Fract Mech, 37(1990): 405-421.

4. Heinimann, M, Bucci, R, Kulak, M, Garratt, M. Improving damage tolerance of aircraft structures through the use of selective reinforcement, Proc. 23rd Symposium of Int Committee on Aeronautical Fatigue, ICAF 2005, Hamburg, June 2005, pp. 197-208.

5. Zhang, X, Li, Y. Damage tolerance and fail safety of welded aircraft wing panels, AIAA Journal, 43(2005): 1613-1623.

6. Colavita, M, Bowler, A, Zhang, X, Irving, PE. Adhesively bonded CFRP straps as fatigue crack growth retarders on AA2024-T3, SAMPE 2006 Conf, Long Beach, April 2006.

7. Ehrström J-C, Muzzolini R, Arsène S, Van der Veen, S. Improving damage tolerance of integrally machined panels. Proc. 23rd Symposium of International Committee on Aeronautical Fatigue, ICAF 2005, Hamburg, June 2005, pp. 79-90.

8. Murphy, A, Quinn, D, Mawwhinney, P, Özakca, M, Van der Veen, S. Tailoring static strength performance of metallic stiffened panels by selective local sub-stiffening, 47th

AIAA/ASME/ASCE/AHS/ASC Structures, Structural Dynamics, and Materials Conference, 1-4 May 2006, Newport, Rhode Island. AIAA 2006-1944.

9. Colombi P, Bassetti A, Nussbaumer A. Delamination effects on cracked steel members reinforced by pre-stressed composite patch, Theoretical and Applied Fracture Mechanics, 39 (2003): 61-71.

10. Poe, CC. Fatigue crack propagation in stiffened panels, Damage Tolerance in Aircraft Structures, 1971, ASTM STP 486, 79-97.

11. Rybicki EF, Kanninen MF. A finite element calculation of stress intensity factors by a modified crack closure integral, Engng. Fract Mech., 9 (1977): 931-938.

12. Krueger, R. The virtual crack closure technique: history, approach and applications, April 2002, NASA/CR-2002-211628, ICASE Report No. 2002-10, ICASE Mail Stop 132C NASA Langley Research Center Hampton, VA 23681-2199, pp.64.

13. Broek, D., Elementary engineering fracture mechanics, Marinus Nijho Publishers, 4th edition, 1986

14. Datoo, MH, Mechanics of Fibrous Composites, 1991. Chapter 7. Pub. Elsevier Applied Science.

15. Tahmasebi, F. Software tools for analysis of bonded joints, NASA/GSFC-code 542, FEMCI workshop, 2001.

16. Zhang, X, Figueroa-Gordon, D, Boscolo, M, Allegri, G, Irving, PE. Improving fail-safety of aircraft integral structures through the use of bonded crack retarders, to be presented at the $24^{\text {th }}$ 
Symposium of International Committee of Aeronautical Fatigue, ICAF 2007, Naples, 16-18 May 2007.

17. Boscolo, M, Zhang, X, Allegri, G. Design and modelling of selective reinforcements for integral aircraft structures. 48th AIAA/ASME /ASCE/AHS/ASC Structures, Structural Dynamics, and Materials Conference, 23-27 April 2007, Hawaii. AIAA-2007-2116.

18. Paris, PC, Gomez, MP, Anderson, WP. A rational analytic theory of fatigue, The Trend in Engineering, 13 (1961): 9-14.

19. Parker, AP. Stress intensity factors, crack profiles, and fatigue crack growth rates in residual stress fields. In Residual Stress Effects in Fatigue, ASTM STP 776, American Society for Testing and Materials, 1982, pp. 13-31.

20. Figueroa-Gordon, D. Fatigue crack growth rate test of 7085-T7651 M(T). Cranfield University, unpublished data, 2007.

21. Cartie, D. Fracture toughness tests of FM94, Cranfield University, unpublished data.

22. Glinka, G. Effect of residual stresses on fatigue crack growth in steel weldments under constant and variable amplitude load. In Fracture Mechanics, ASTM STP 677, American Society for Testing and Materials, 1979, pp. 198-214.

Table 1 Substrate material properties, density, and thickness*

\begin{tabular}{l|l|l}
\hline Material & $2024-\mathrm{T} 351$ & $7085-\mathrm{T} 7651$ \\
\hline${\text { Young's modulus }(E)(\mathrm{GPa})^{a}}^{a}$ & 72 & 71 \\
${\text { Poisson's ratio }(v)^{a}}^{\mathrm{CTE}(\alpha)^{\mathrm{a}}}$ & 0.33 & 0.33 \\
Density $(\rho)\left(\mathrm{g} / \mathrm{cm}^{3}\right)^{a}$ & 23.6 & 23.6 \\
\hline Thickness $(t)(\mathrm{mm})$ & 2.77 & 2.77 \\
\hline Paris law constants $C, n$ & 1.6 & 10 \\
\hline$\sigma_{\mathrm{ys}}(\mathrm{MPa})$ & $1.1 \mathrm{E}-10,2.6^{b}$ & $6.19 \mathrm{E}-10,2.791^{c}$ \\
\hline$K_{I C}$ plane strain $\left(\mathrm{MPa} \mathrm{m}{ }^{1 / 2}\right)$ & $365.4^{d}$ & $480^{e}$ \\
\hline $\begin{array}{l}\text { Fracture toughness } K_{C} \text { for the } \\
\text { given thickness }\left(\mathrm{MPa} \mathrm{m}{ }^{1 / 2}\right)^{f}\end{array}$ & 72.37 & $25^{e}$ \\
\hline
\end{tabular}

*Data sources: $a$. http://www.aerospacemetals.com/, accessed March 2007; $b$. from [6]; $c$. computed from $d a / d N$ vs. $\Delta K$ data by tests carried out at Cranfield University; $d$. NASGRO database in AFGROW package for 2024-T3 plt \& sht; $e$. Alcoa test data; $f$. computed using the NASGROW interpolation equation based on plane-strain and plane-stress fracture toughness. AFGROW website: http://www.siresearch.info/projects/afgrow/index.php 
Table 2 Adhesive and strap material properties, density, and thickness

\begin{tabular}{|c|c|c|c|c|c|c|}
\hline Material & $\begin{array}{c}\text { Adhesive } \\
\text { REDUX } \\
810^{a}\end{array}$ & $\begin{array}{l}\text { Adhesive } \\
\text { FM } 94^{b}\end{array}$ & $\begin{array}{c}\text { CFRP } \\
\mathrm{M}^{2} 1-\mathrm{T} 800^{c}\end{array}$ & $\begin{array}{c}\text { CFRP } \\
\text { Cycom919HF- } \\
42 \%-\mathrm{HS}\end{array}$ & $\begin{array}{c}\text { GFRP } \\
\text { Hexcel } 913\end{array}$ & Ti-6Al- $4 V^{f}$ \\
\hline Geometry & $\mathrm{M}(\mathrm{T})$ & SENT & $\mathrm{M}(\mathrm{T})$ & SENT & SENT & SENT \\
\hline $\begin{array}{l}\text { Thickness } \\
\text { (mm) }\end{array}$ & 0.2 & 0.2 & $\begin{array}{l}1 \times 0.25 \\
2 \times 0.25\end{array}$ & $16 \times 0.125$ & $16 \times 0.125$ & 2.0 \\
\hline$E_{11}(\mathrm{GPa})$ & 1.9 & 1.9 & 171 & $135^{d}$ & $40^{e}$ & 113.8 \\
\hline$E_{22}(\mathrm{GPa})$ & 1.9 & 1.9 & 17.2 & $5.78^{e}$ & $10^{e}$ & 113.8 \\
\hline$G_{12}(\mathrm{GPa})$ & 0.621 & 0.621 & 5.1 & $4^{b}$ & $5^{b}$ & 44 \\
\hline$v_{12}$ & 0.52 & 0.52 & 0.42 & $0.28^{b}$ & $0.28^{b}$ & 0.342 \\
\hline$\sigma_{\mathrm{ys}}(\mathrm{MPa})$ & I & I & I & I & I & 900 \\
\hline$\alpha_{11}\left(\mu^{\circ} \mathrm{C}\right)$ & / & I & 2.1 & $-0.3^{b}$ & $3.6^{b}$ & 8.6 \\
\hline$\alpha_{22}\left(\mu^{\circ} \mathrm{C}\right)$ & I & I & 24 & $30^{b}$ & $21^{b}$ & 8.6 \\
\hline$\rho\left(\mathrm{g} / \mathrm{cm}^{3}\right)$ & 1.1 & 1.1 & 1.8 & $1.8^{b}$ & $2^{b}$ & 4.51 \\
\hline$G_{I C}\left(\mathrm{~J} / \mathrm{m}^{2}\right)$ & 100 & $2500^{g}$ & $250^{h}$ & $250^{h}$ & I & I \\
\hline$G_{I I C}\left(\mathrm{~J} / \mathrm{m}^{2}\right)$ & 400 & $9000^{g}$ & $500^{h}$ & $500^{h}$ & I & I \\
\hline
\end{tabular}

Data sources: $a$. Redux 810 data sheet from Hexcel Composites website: http://www.hexcel.com/NR/ rdonlyres/300F1E88-33B3-4452-8DDC-106BB1E9F58C/0/Redux810_us.pdf, accessed March 2007; $b$. typical generic values; $c$. from [6]; $d$. Cytec data sheets; $e$. hand calculation by the rule of mixture; $f$. http://www.aerospacemetals.com/, accessed March 2007; g. [21]; $h$. from: Perry, Jr. McKelvie, Experimental Mechanics, 1996, 36: 55 -63; Lee, Lee, Fu, Composite Structures, 1998, 41: 229-241. Note: these values are listed here fore reference; delamination was not modelled in this paper. 


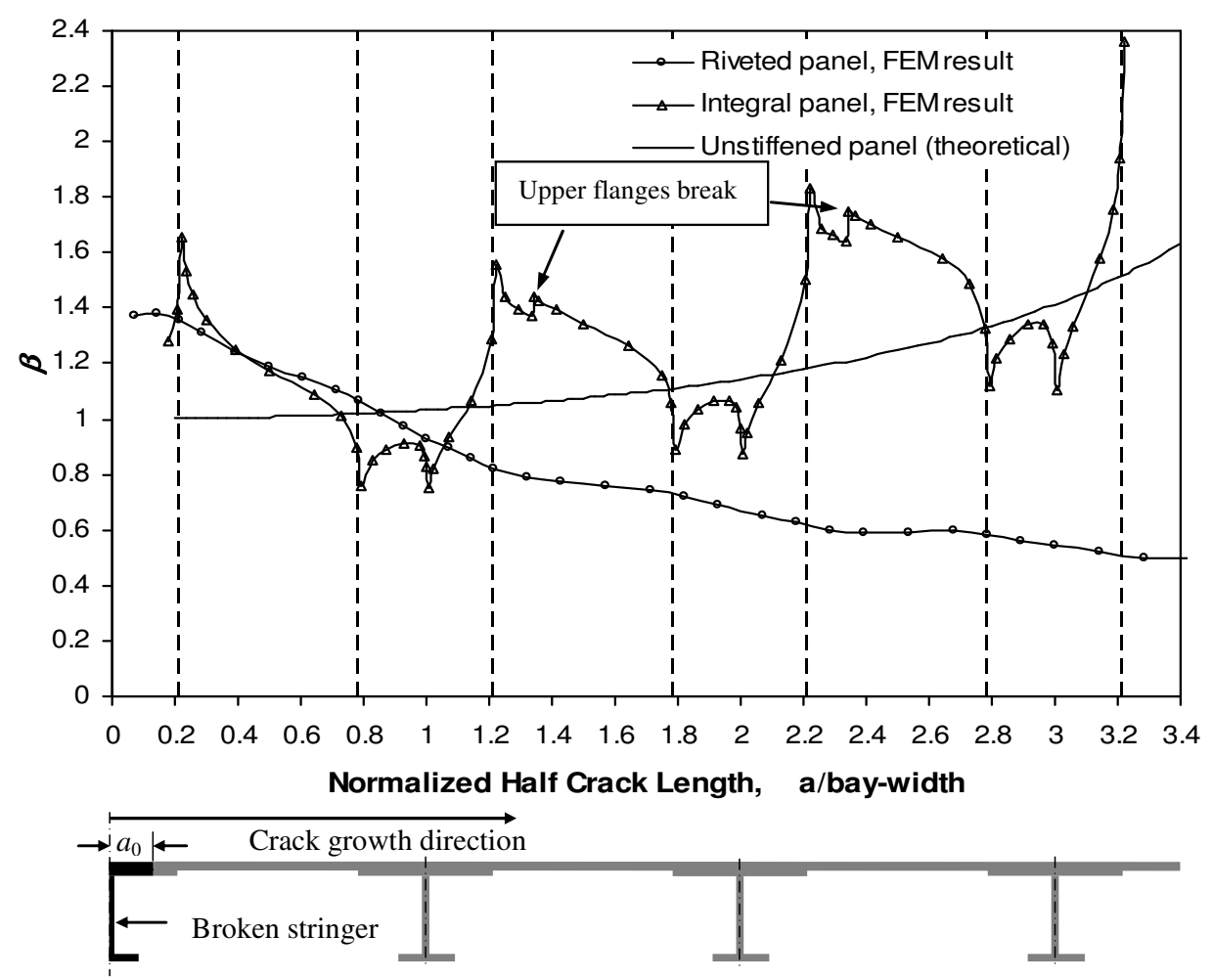

Fig. 1 Calculated stress intensity factor coefficient $(\beta)$ of riveted, integral and unstiffened panels, showing half panel width and the scenario of skin crack under broken central stringer [5].

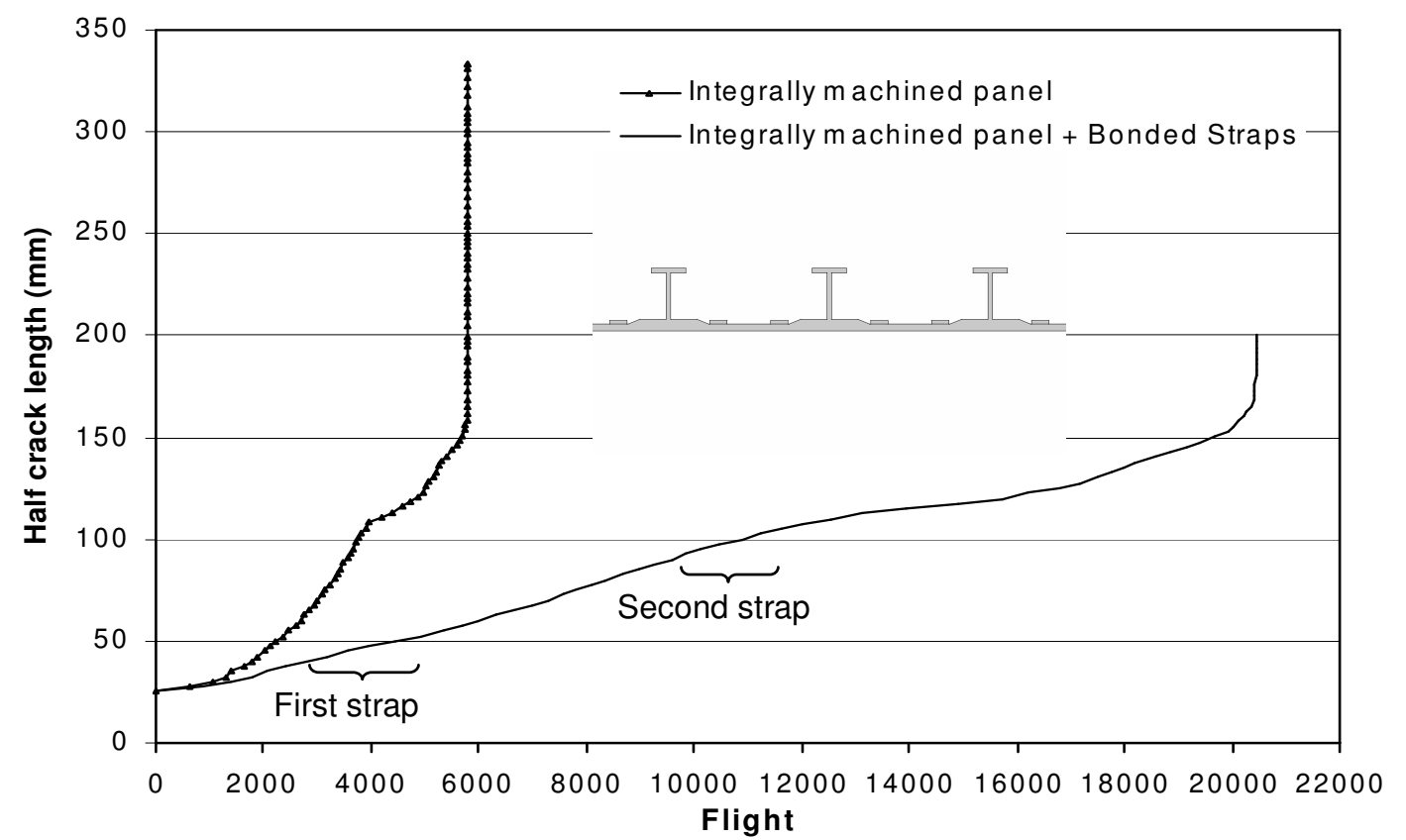

Fig. 2 Predicted crack growth lives for integrally stiffened panels with and without crack retarder straps [5]. Strap was made of unidirectional CFRP, $15 \mathrm{~mm}$ wide and 3 $\mathrm{mm}$ thick, and was assumed to be cured at room temperature. Variable amplitude load spectrum $\left(\sigma_{\max }=138 \mathrm{MPa}\right)$ was applied in the analysis. 


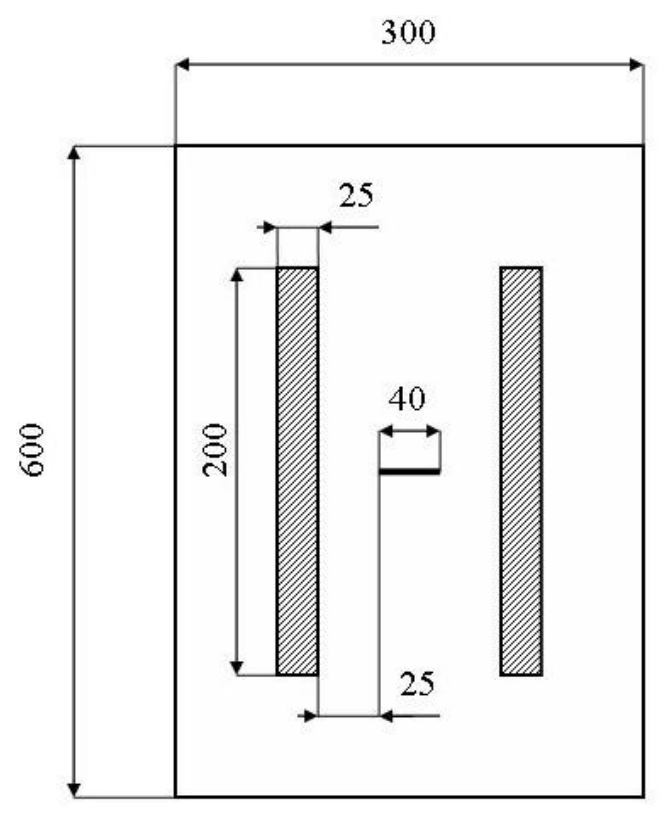

(a) $\mathrm{M}(\mathrm{T})$

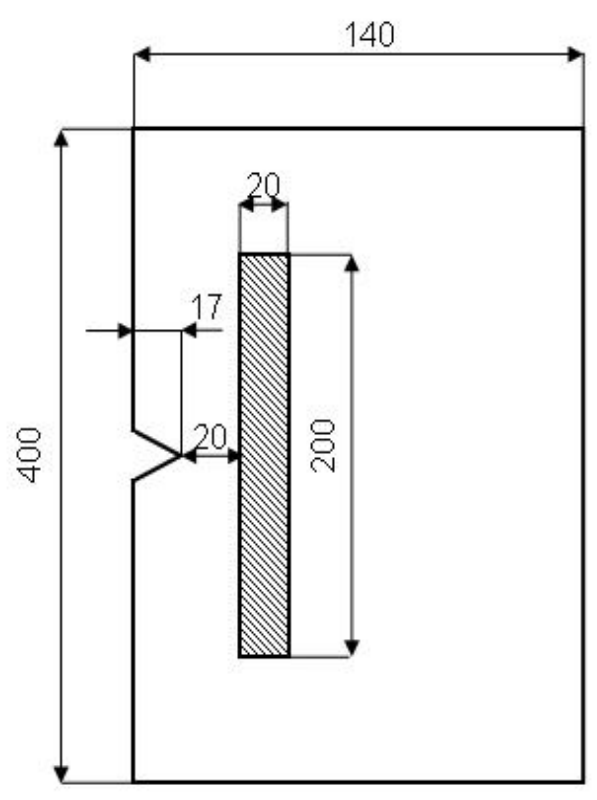

(b) SENT

Fig. 3 Specimens tested and modelled in this study. Dimensions in mm (not to scale).

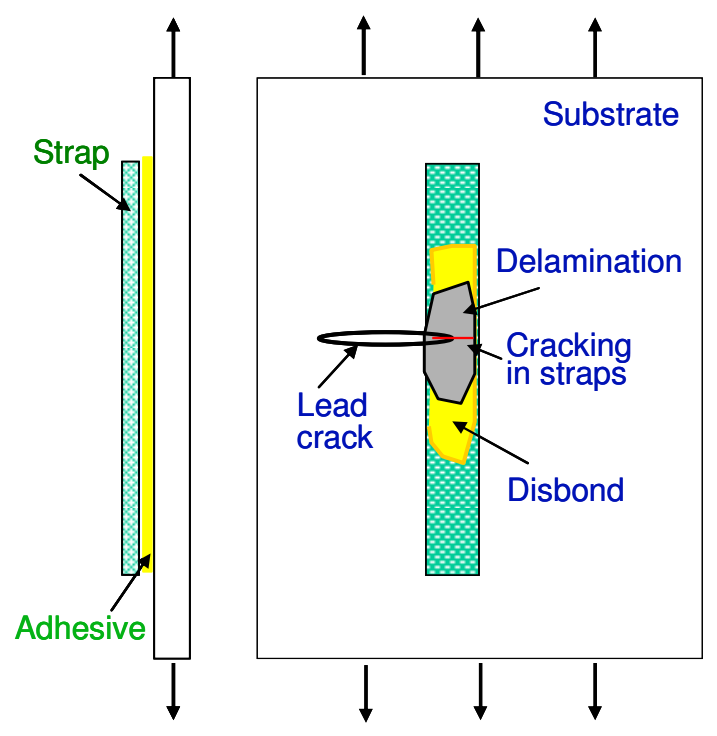

(a)

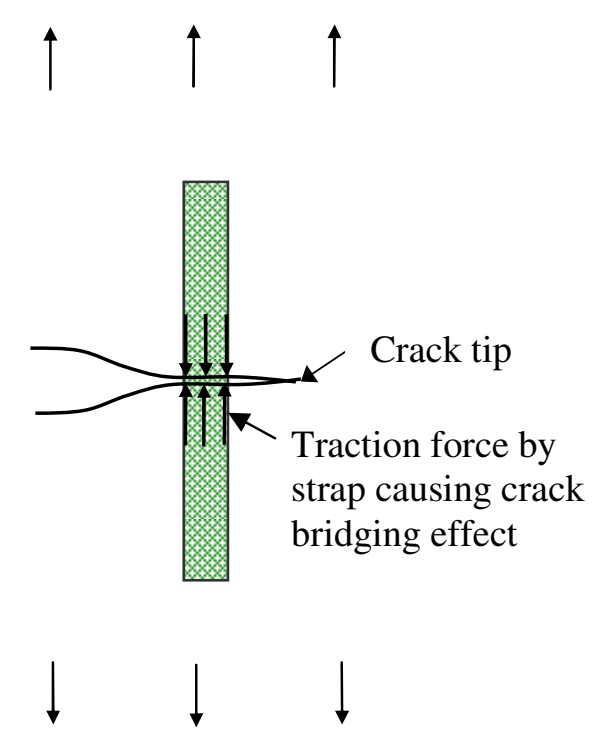

(b)

Fig. 4 (a) A bonded structure and four possible damage modes; local stiffening effect due to the strap; (b) bridging effect by strap traction force. 

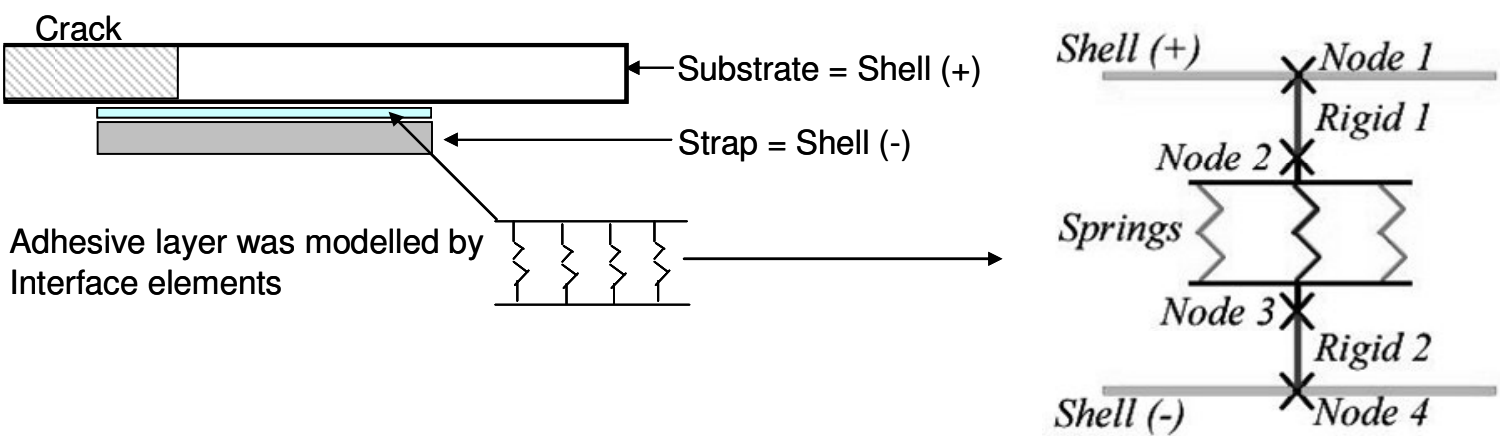

Fig. 5 Interface elements to model delamination/disbond initiation \& propagation.

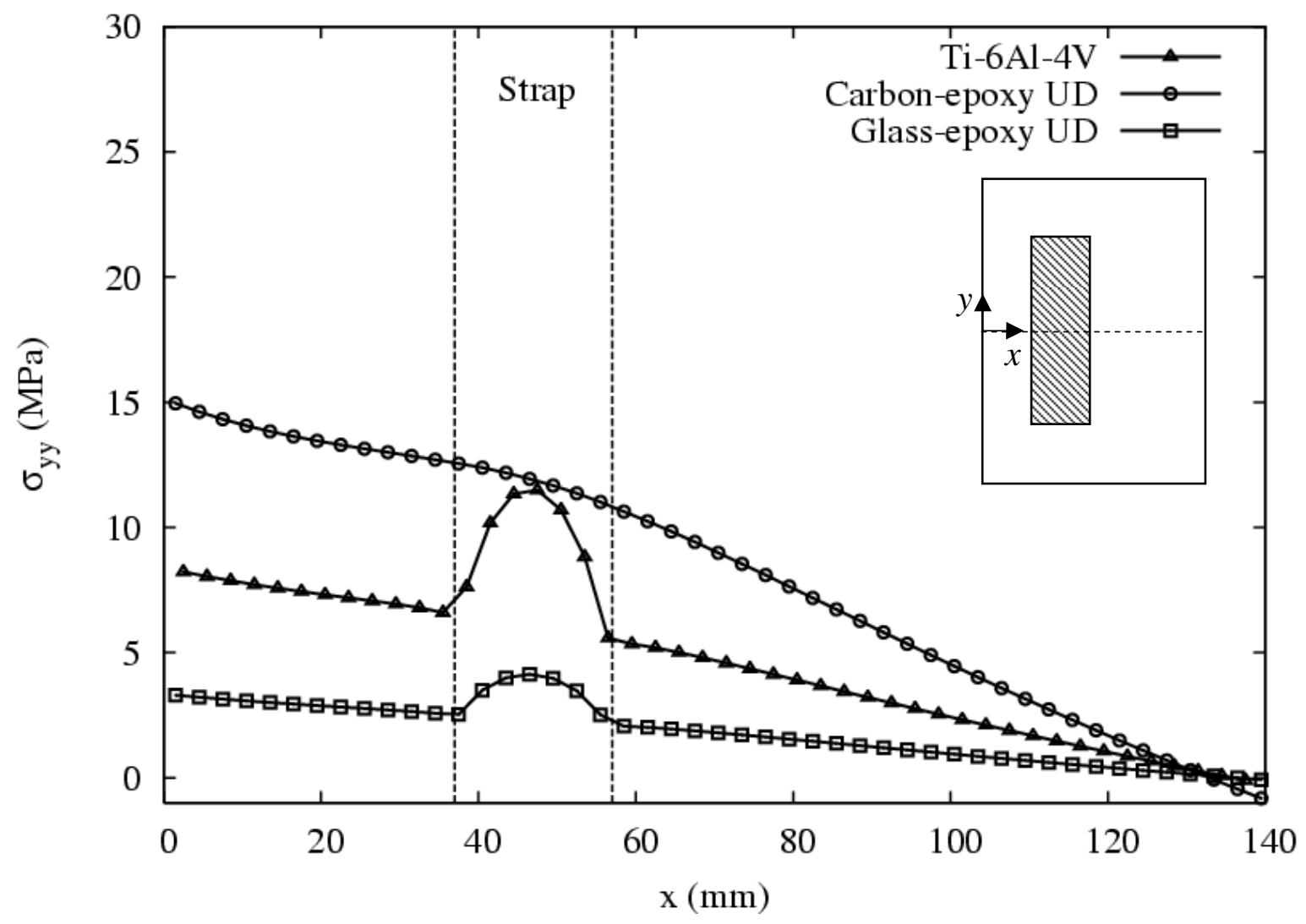

Fig. 6(a) Residual stress distributions in the substrate of a $10 \mathrm{~mm}$ thick un-notched sample of the same dimensions of the SENT specimen and bonded with straps made of Ti-6-4 alloy, carbon-epoxy, and glass-epoxy strap; all were cured at $120^{\circ} \mathrm{C}$, strap width $20 \mathrm{~mm}$, thickness 2 $\mathrm{mm}$. 


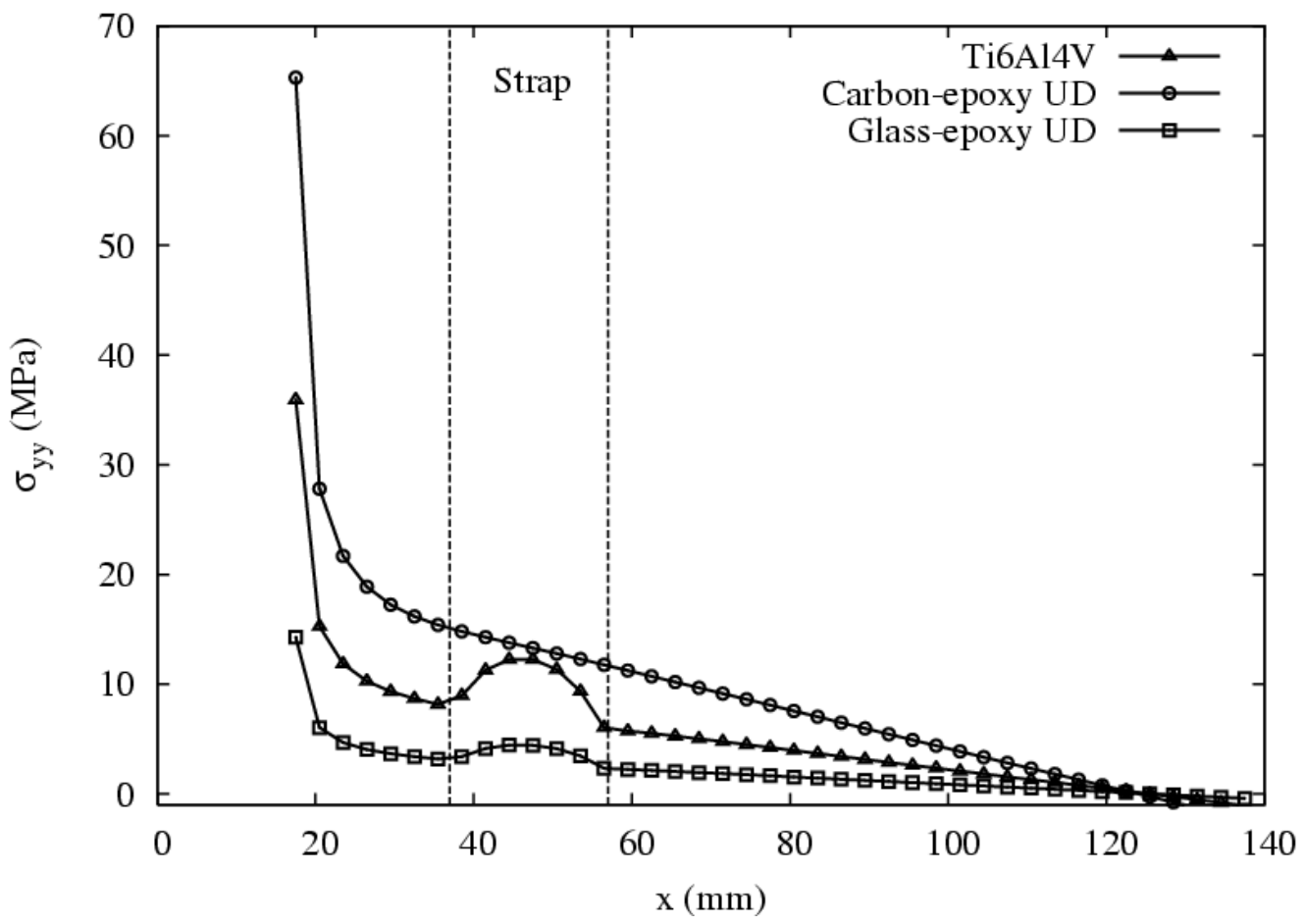

Fig. 6(b) Residual stress distributions in the substrate of $10 \mathrm{~mm}$ thick SENT sample (notch length $=17 \mathrm{~mm}$ ) bonded with straps made of Ti-6-4 alloy, carbon-epoxy, and glass-epoxy strap; all were cured at $120^{\circ} \mathrm{C}$, strap width $=20 \mathrm{~mm}$, thickness $=2 \mathrm{~mm}$.

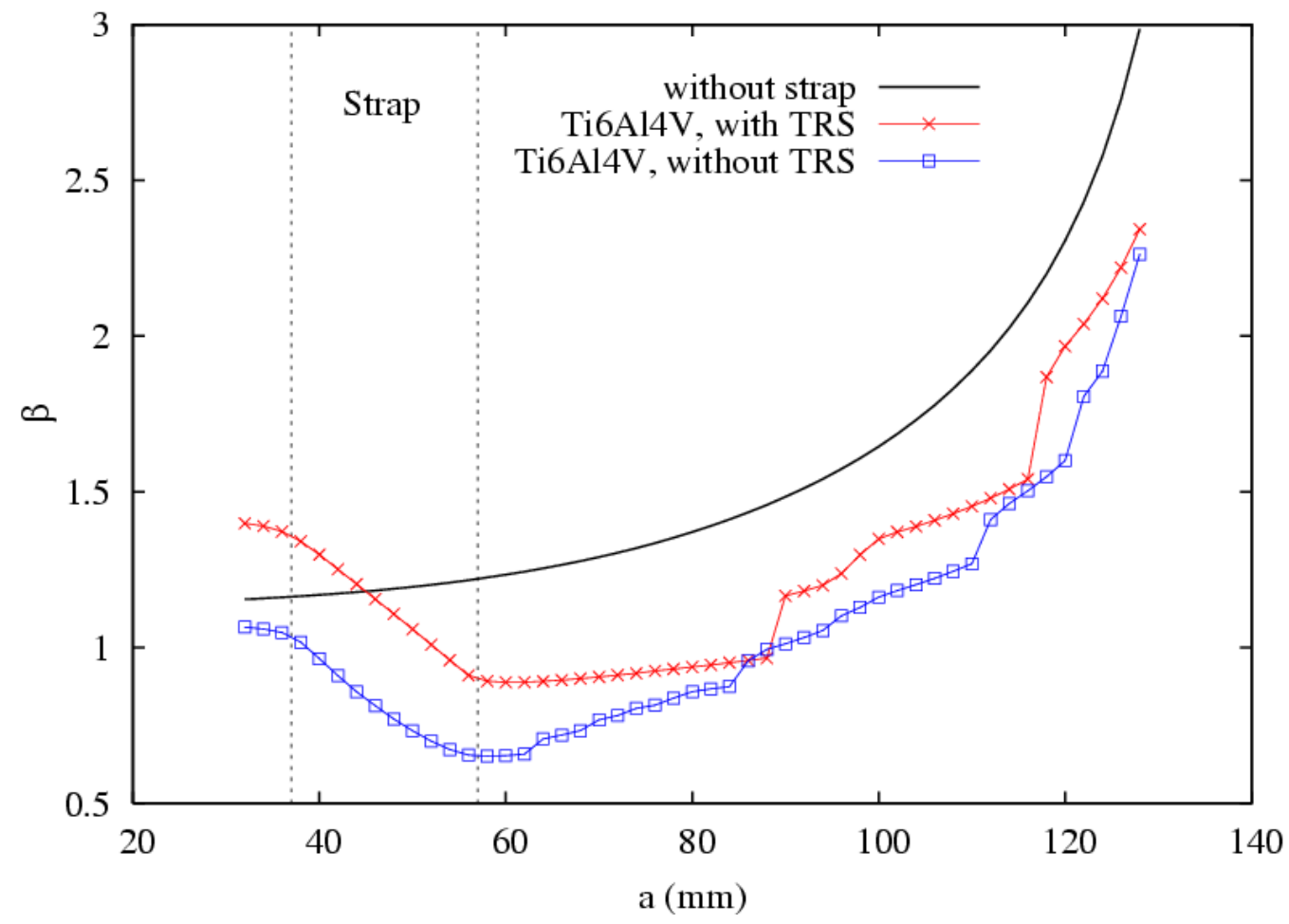

Fig. 7 Calculated $\beta$ functions with and without residual stress (TRS) effect: $10 \mathrm{~mm}$ thick SENT sample with Ti-6-4 strap cured at $120^{\circ} \mathrm{C}$ and $20^{\circ} \mathrm{C}$. Strap width $20 \mathrm{~mm}$, thickness 2 $\mathrm{mm}$. 


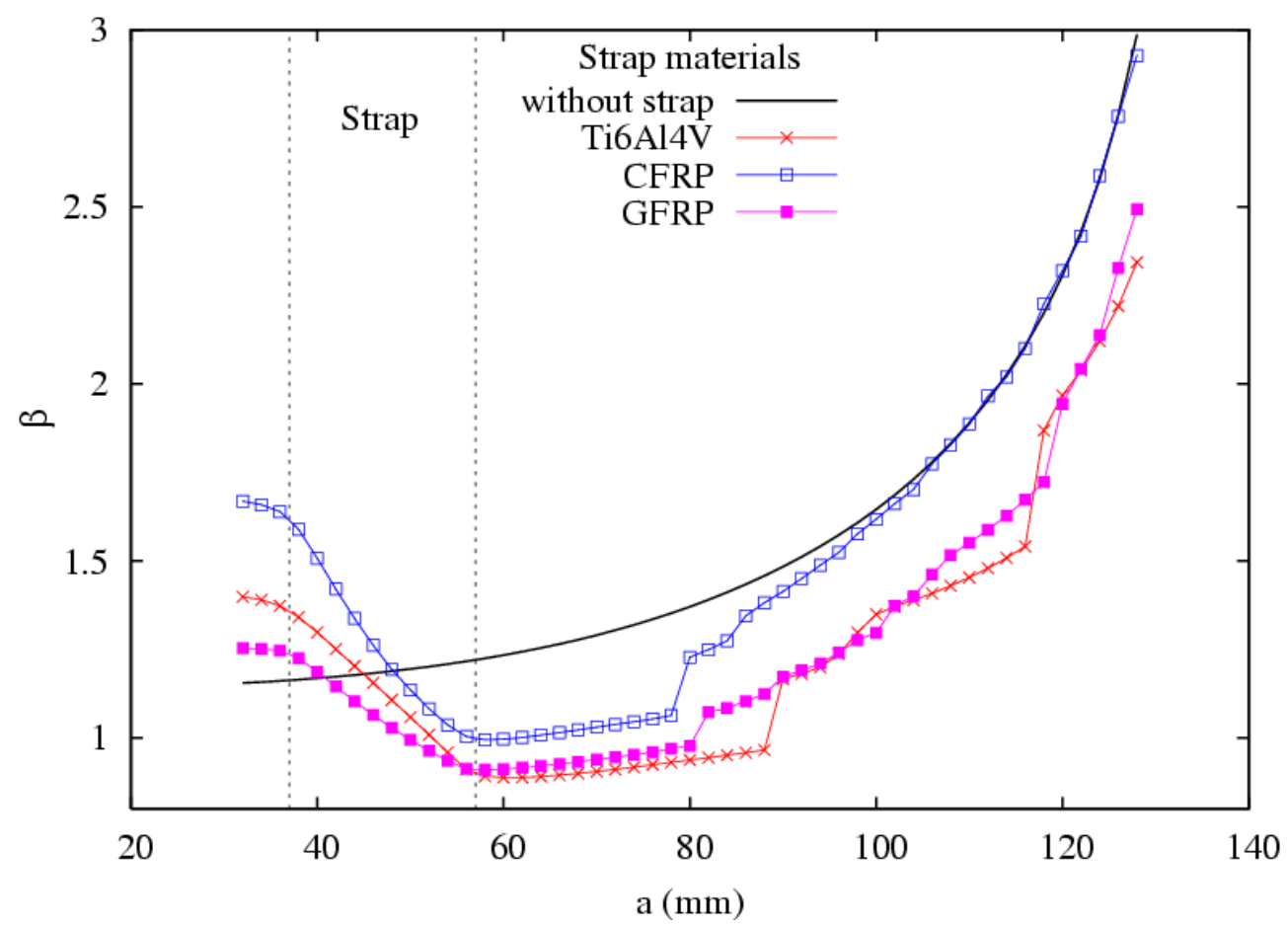

Fig. 8 Calculated $\beta$ functions with residual stress effect: $10 \mathrm{~mm}$ thick SENT samples with three different strap materials all cured at $120^{\circ} \mathrm{C}$. strap width $20 \mathrm{~mm}$, thickness $2 \mathrm{~mm}$.

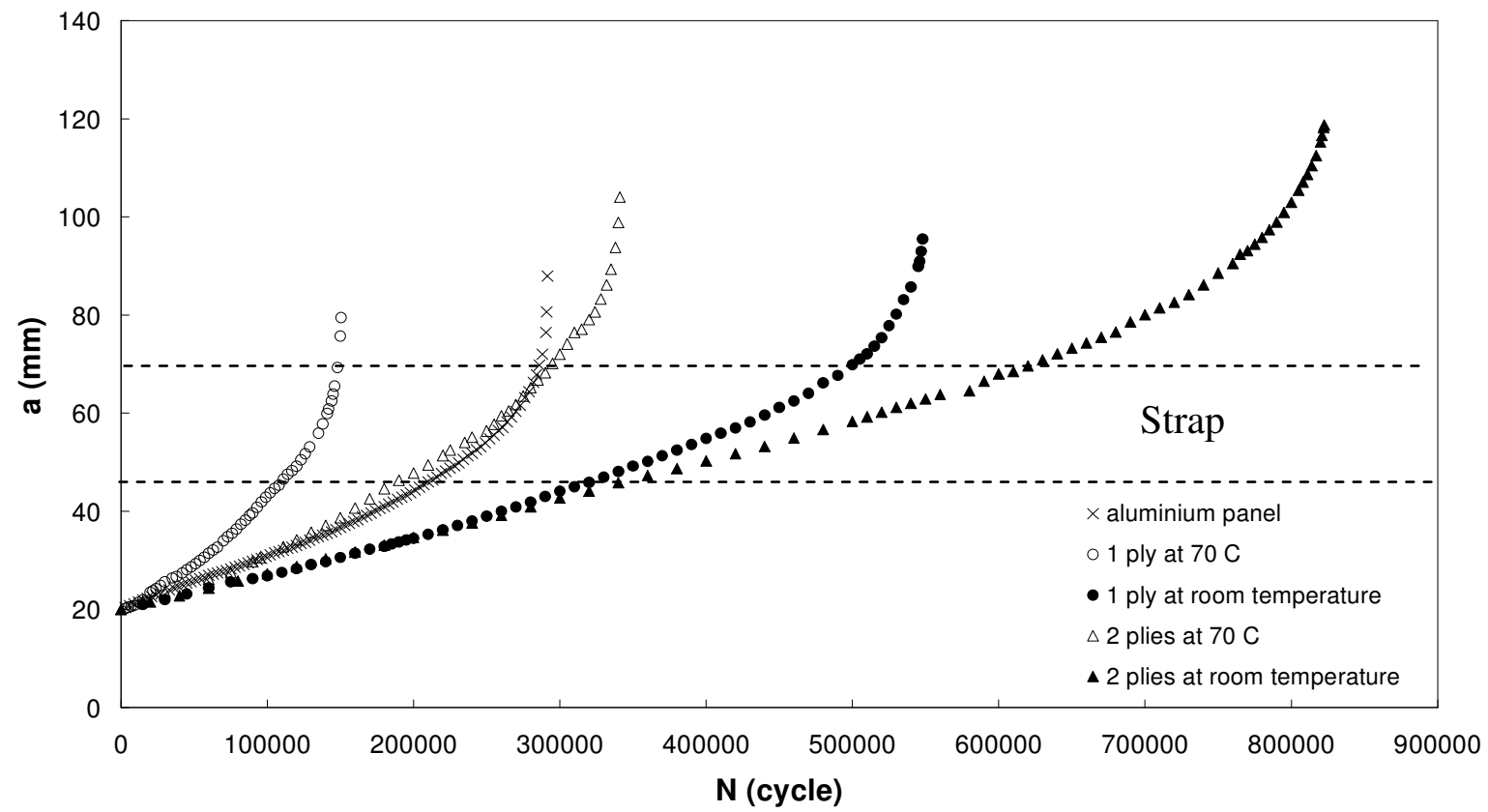

Fig. 9 Measured crack growth histories with residual stress effect: $1.6 \mathrm{~mm}$ thick $\mathrm{M}(\mathrm{T})$ samples cured at $70^{\circ} \mathrm{C}$ and room temperature (RT), respectively [6]. 


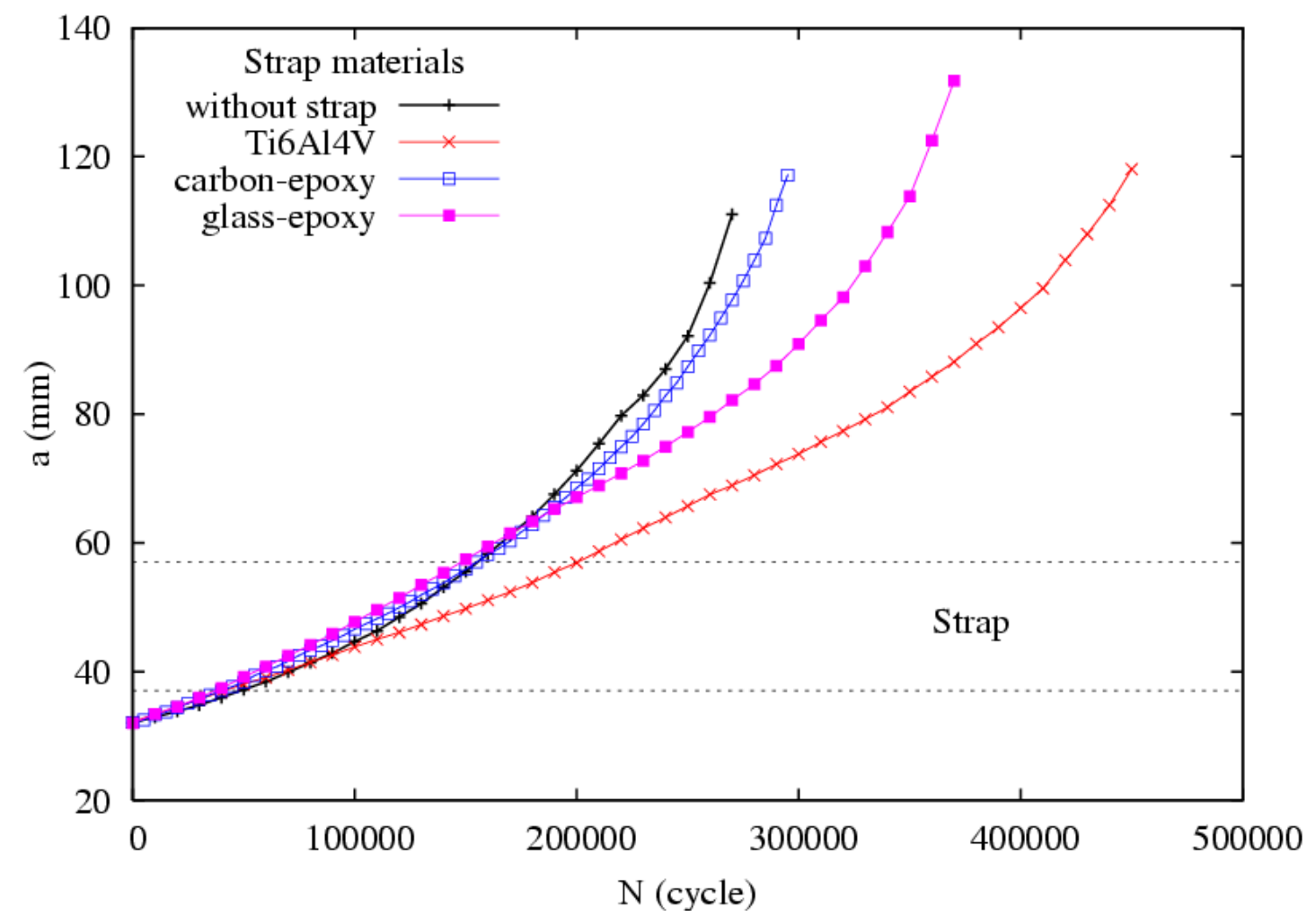

Fig. 10 Measured crack growth histories with residual stress effect: $10 \mathrm{~mm}$ thick SENT samples cured at $120^{\circ} \mathrm{C}$; strap width $20 \mathrm{~mm}$, thickness $2 \mathrm{~mm}$.

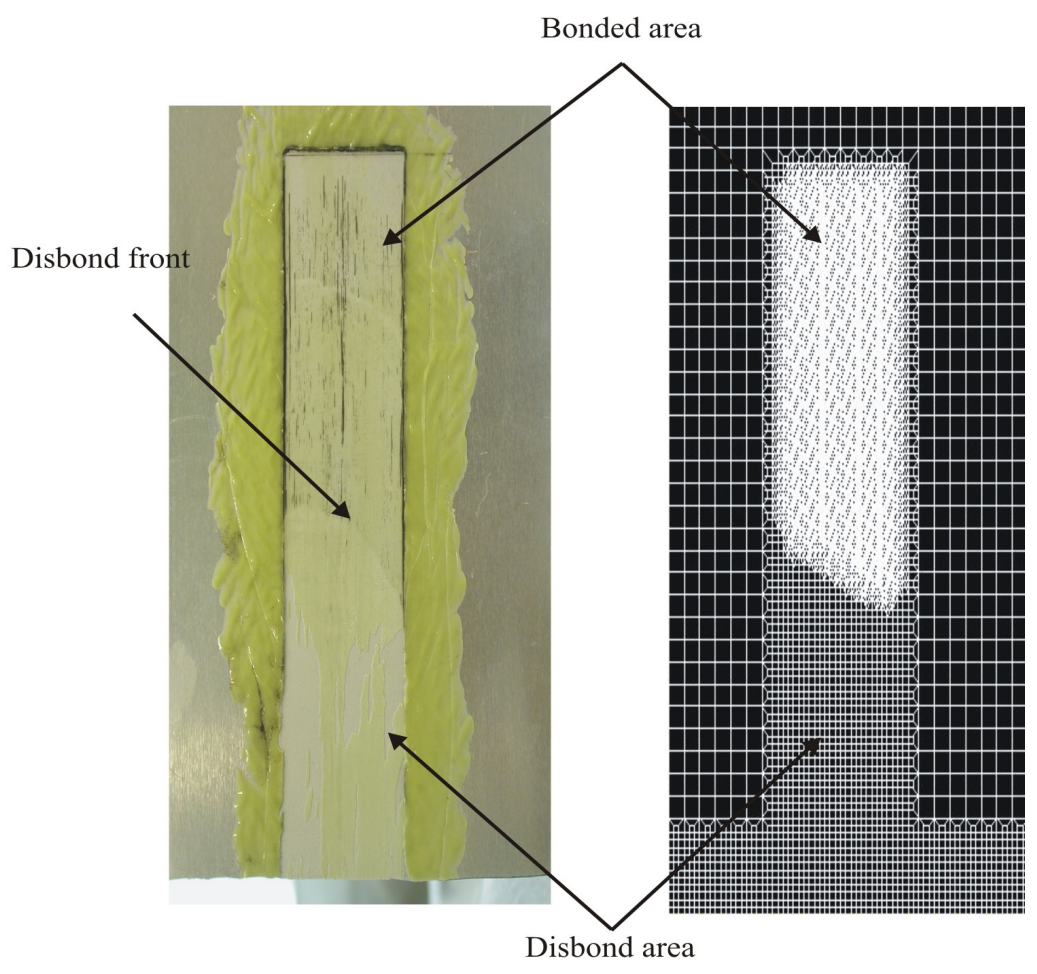

Fig. 11 (a) $\mathrm{M}(\mathrm{T})$ sample with carbon strap cured at RT: measured and predicted disbond failure. 


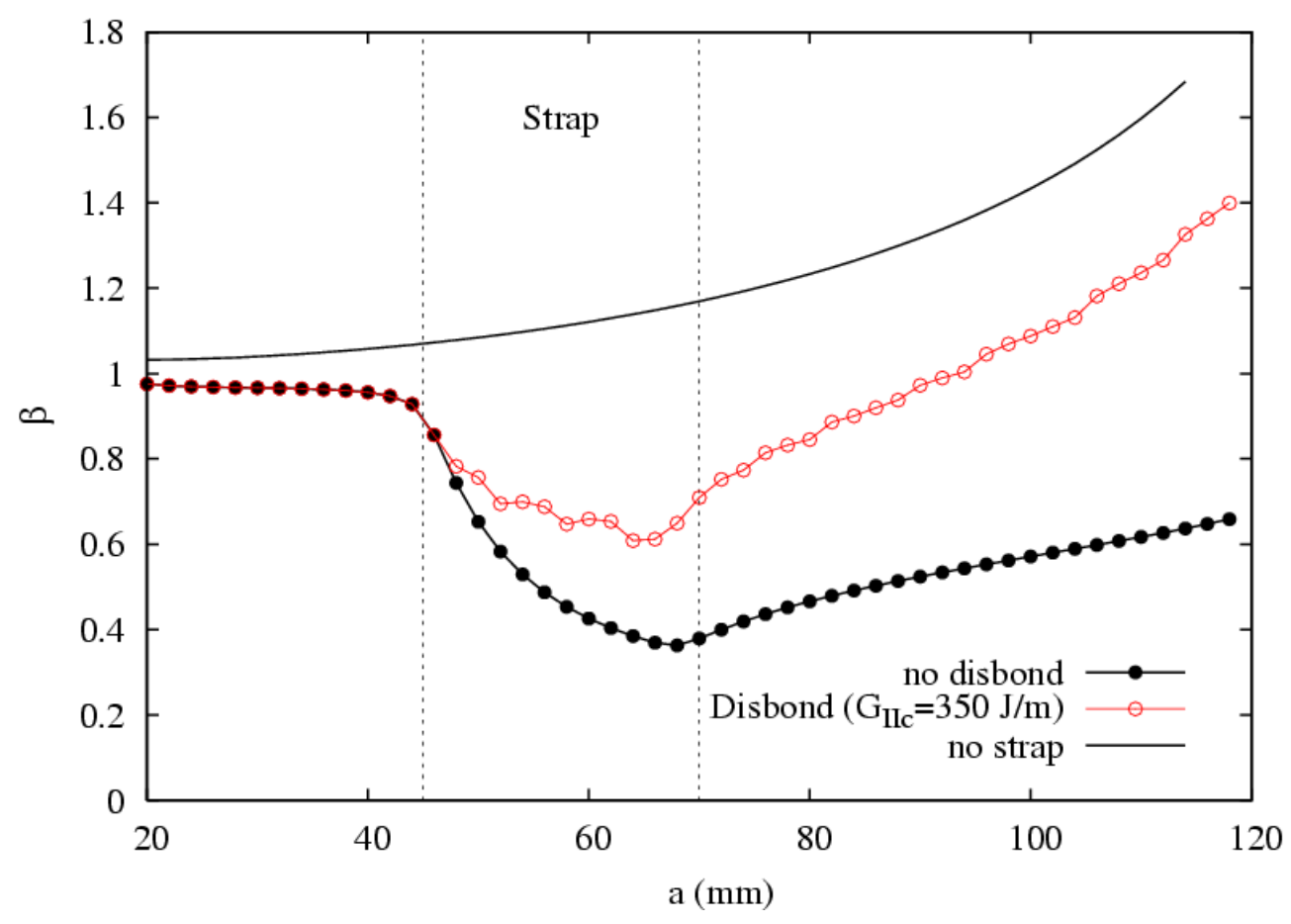

Fig. 11 (b) $\mathrm{M}(\mathrm{T})$ sample with carbon strap cured at RT: calculated $\beta$ functions with and straps.

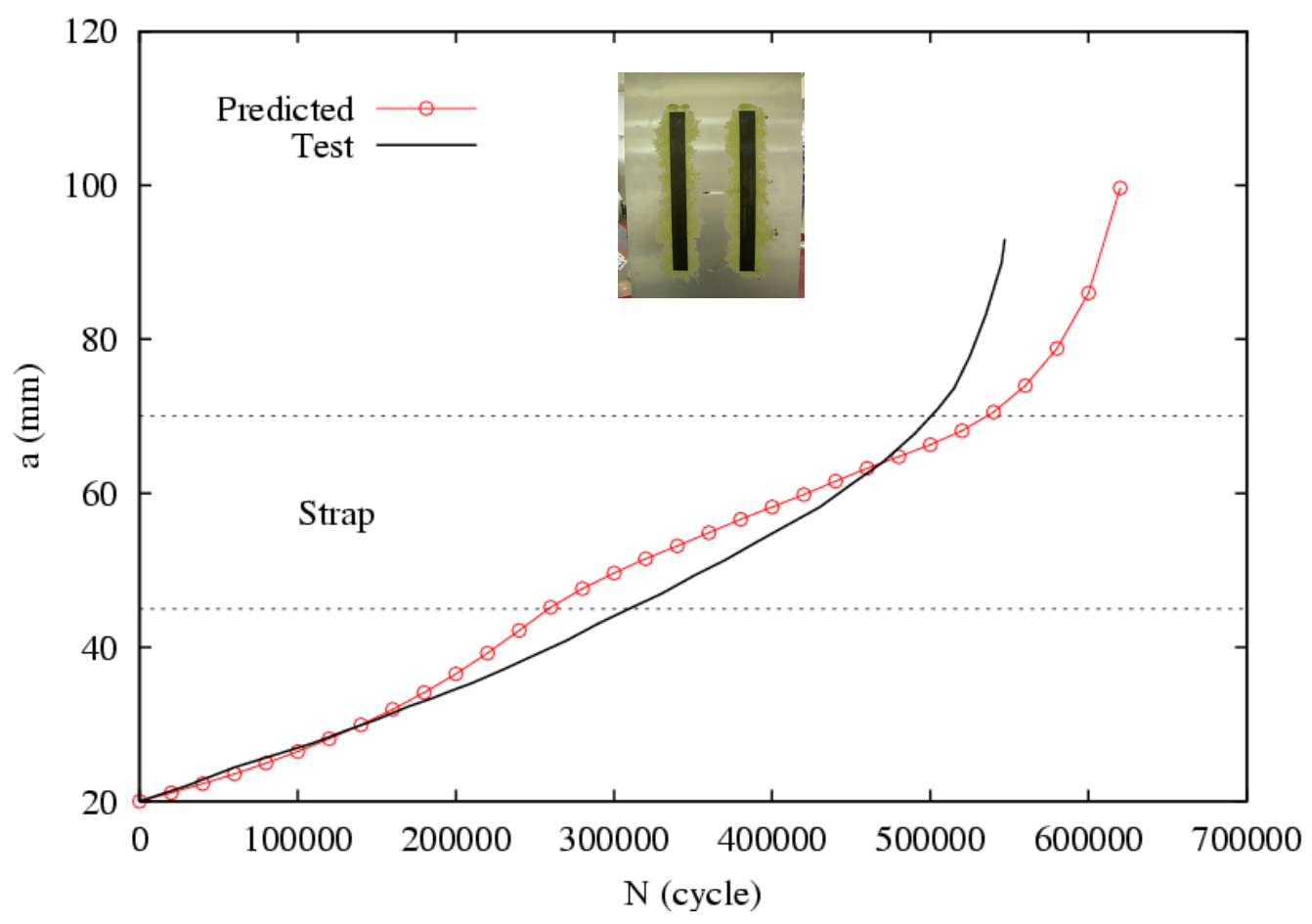

Fig. 11 (c) $M(T)$ sample with carbon strap cured at RT: predicted and measured fatigue crack growth life (room temperature cure case). 


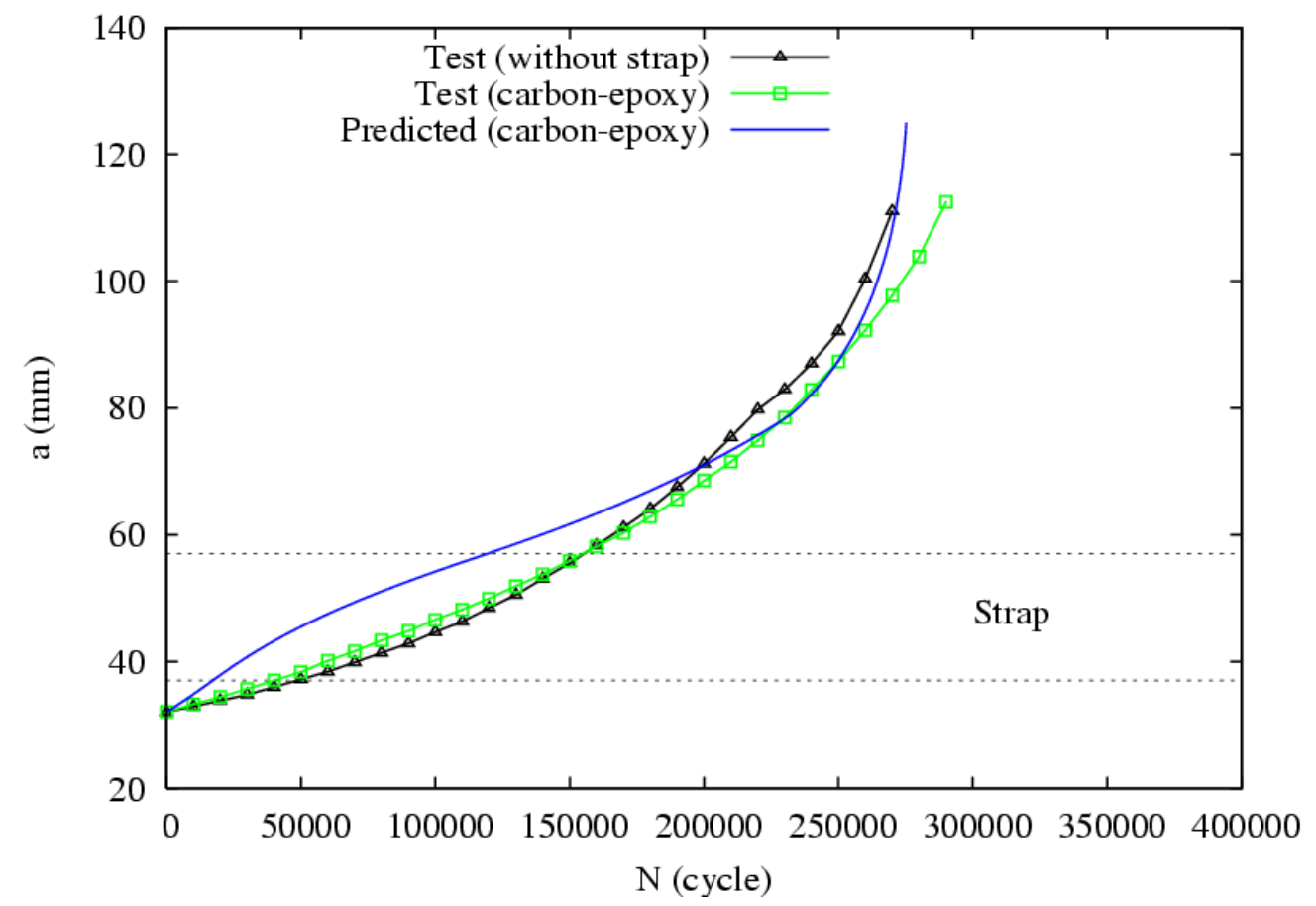

Fig. 12 (a) SENT sample with CFRP strap: fatigue crack growth lives: prediction vs. experimental tests (strap width $20 \mathrm{~mm}$, thickness $2 \mathrm{~mm}$ ).

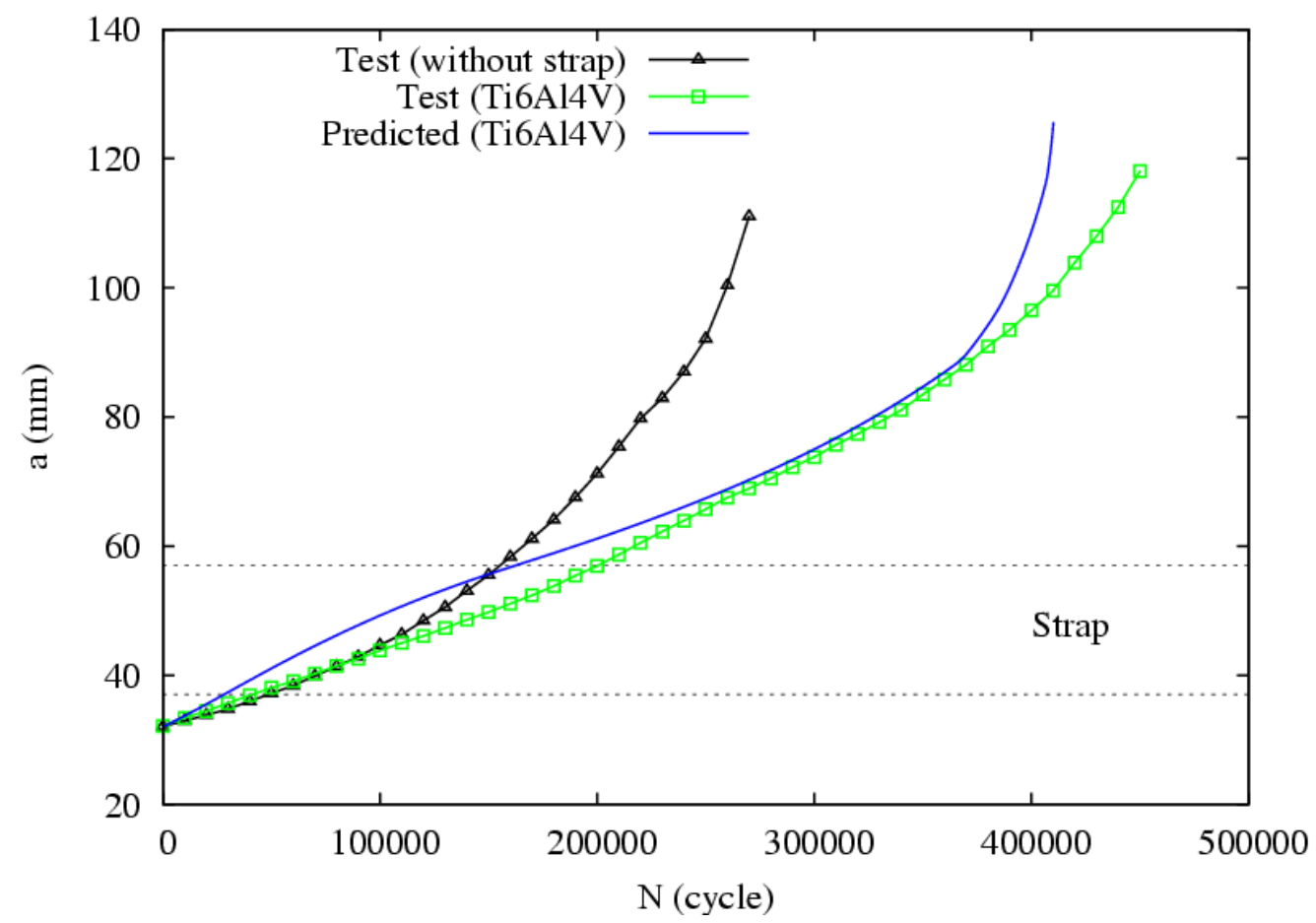

Fig. 12 (b) SENT sample with Ti-6-4 strap: fatigue crack growth lives: prediction vs. experimental tests (strap width $20 \mathrm{~mm}$, thickness $2 \mathrm{~mm}$ ). 


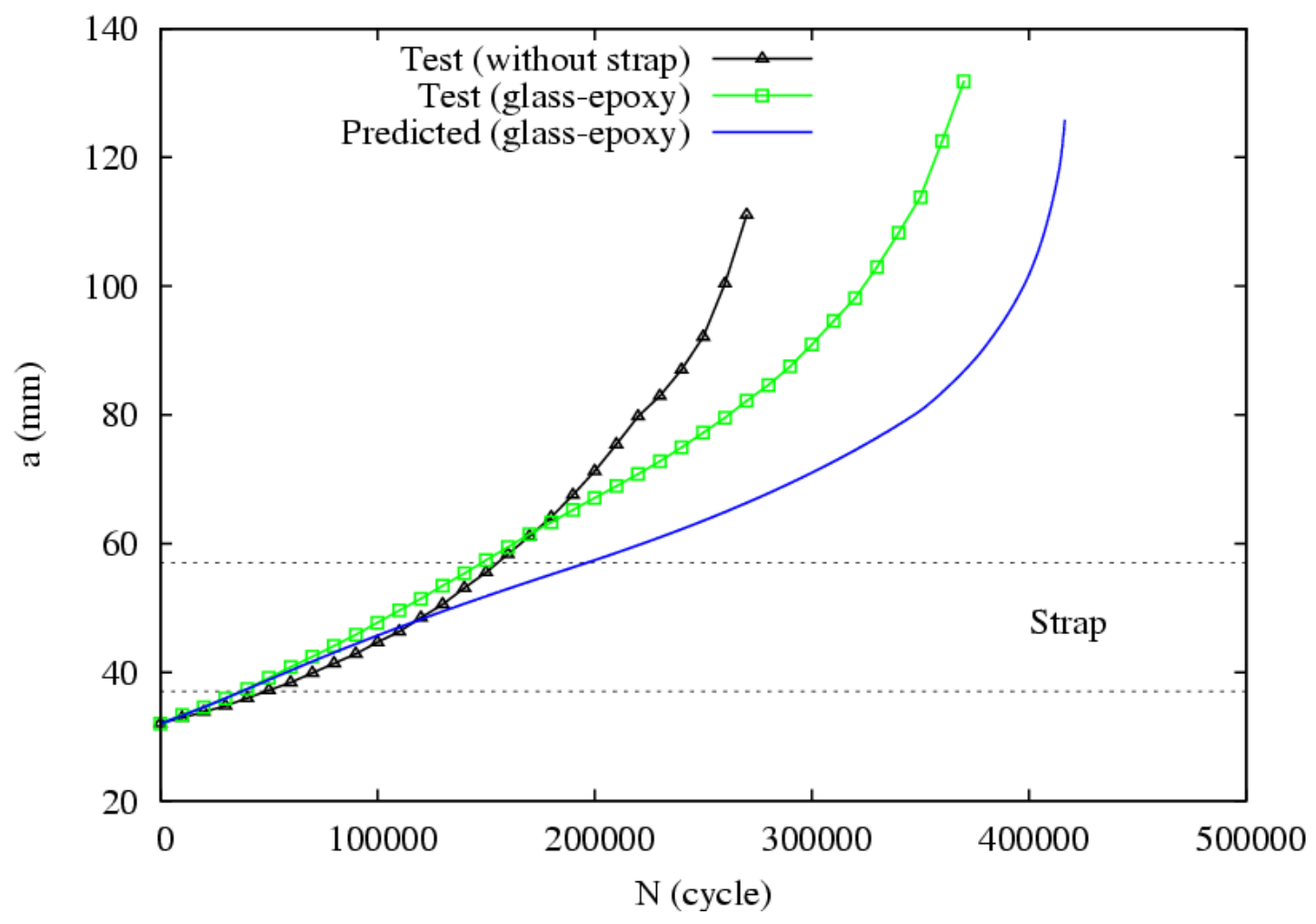

Fig. 12 (c) SENT sample with GFRP strap: fatigue crack growth lives: prediction vs. experimental tests (strap width $20 \mathrm{~mm}$, thickness $2 \mathrm{~mm}$ ). 